\title{
Drought and heat stress-related proteins: an update about their functional relevance in imparting stress tolerance in agricultural crops
}

\author{
Manu Priya ${ }^{1} \cdot$ Om P. Dhanker ${ }^{2} \cdot$ Kadambot H. M. Siddique $^{3} \cdot$ Bindumadhava HanumanthaRao $^{4}$. \\ Ramakrishnan M. Nair ${ }^{4}$. Sarita Pandey ${ }^{5} \cdot$ Sadhana Singh $^{5} \cdot$ Rajeev K. Varshney $^{5} \cdot$ P. V. Vara Prasad ${ }^{6} \cdot$ Harsh Nayyar $^{1}$
}

Received: 26 May 2018 / Accepted: 19 March 2019

○) Springer-Verlag GmbH Germany, part of Springer Nature 2019

\begin{abstract}
Key message We describe here the recent developments about the involvement of diverse stress-related proteins in sensing, signaling, and defending the cells in plants in response to drought or/and heat stress.

Abstract In the current era of global climate drift, plant growth and productivity are often limited by various environmental stresses, especially drought and heat. Adaptation to abiotic stress is a multigenic process involving maintenance of homeostasis for proper survival under adverse environment. It has been widely observed that a series of proteins respond to heat and drought conditions at both transcriptional and translational levels. The proteins are involved in various signaling events, act as key transcriptional activators and saviors of plants under extreme environments. A detailed insight about the functional aspects of diverse stress-responsive proteins may assist in unraveling various stress resilience mechanisms in plants. Furthermore, by identifying the metabolic proteins associated with drought and heat tolerance, tolerant varieties can be produced through transgenic/recombinant technologies. A large number of regulatory and functional stress-associated proteins are reported to participate in response to heat and drought stresses, such as protein kinases, phosphatases, transcription factors, and late embryogenesis abundant proteins, dehydrins, osmotins, and heat shock proteins, which may be similar or unique to stress treatments. Few studies have revealed that cellular response to combined drought and heat stresses is distinctive, compared to their individual treatments. In this review, we would mainly focus on the new developments about various stress sensors and receptors, transcription factors, chaperones, and stress-associated proteins involved in drought or/ and heat stresses, and their possible role in augmenting stress tolerance in crops.
\end{abstract}

\section{Introduction}

Communicated by Lizhong Xiong.

Harsh Nayyar

harshnayyar@hotmail.com

Department of Botany, Panjab University, Chandigarh, India

2 Stockbridge School of Agriculture, University of Massachusetts Amherst, Amherst, MA 01003, USA

3 The UWA Institute of Agriculture, University of Western Australia, Perth, WA, Australia

4 World Vegetable Center, South Asia, Hyderabad, India

5 Center of Excellence in Genomics and Systems Biology, International Crops Research Institute for the Semi-Arid Tropics, Patancheru, Hyderabad, Telangana 502324, India

6 Sustainable Intensification Innovation Lab, Kansas State University, Manhattan, KS, USA
Abiotic stresses negatively influence plant growth and productivity and are the primary cause of extensive agricultural losses worldwide (Ye et al. 2017). Reduction in crop yield due to environment variations has increased steadily over the last decades (Boyer et al. 2013). Abiotic stress weakens the growth and fitness of the plants, and these stresses include water surplus/deficit, ion toxicity/deficiency, temperature extremes (heat and cold), salinity, and tropospheric ozone. It is assessed that around 50-70\% decline in the crop productivity is due to various abiotic stresses (Verma and Deepti 2016). Several crop production models project a reduction in the crop yields of major agricultural crops in future, mostly due to climatic change (Rosenzweig et al. 2014).

Due to their sedentary nature, plants are unable to elude from unfavorable conditions, so they need robust defense mechanisms to confront unfavorable environmental changes (Kaldenhoff and Fischer 2006). Abiotic constraints, mainly 
drought, and heat stress, may act alone, but frequently act together, and plants have acquired efficient adaptive and protective means to counteract this combined adversity (Zandalinas et al. 2018; Fig. 1). Basic tolerance mechanisms in plants involve the activation of different stress-regulated genes through integrated cellular as well as molecular responses (Latif et al. 2016).

Plants respond to their immediate surroundings by diverse ways, which assist the cells to adapt and achieve cellular homeostasis (Jones 2006). Several diverse proteins have been identified, which play pivotal roles in sustaining homeostasis and attaining stress resilience in plants (PérezClemente et al. 2013). Overexpression of stress-induced genes through transgenic routes is one of the prevalent and most practical approaches in the production of stress-tolerant varieties (Guerra et al. 2015). A pressing number of genes involved in drought and heat stress resilience have been analyzed and attested (Wang et al. 2016b). Cellular proteins are related to signaling and transcriptional regulation and include osmotins, dehydrins, LEA, and lineages of NAM, ATF and CUC (NAC) transcription factors that are intermittently reported as being engaged in stress tolerance (Nouri and Komatsu 2013; Vishwakarma et al. 2017; Fig. 1).

Drought and temperature stresses are the most vital among all the abiotic stresses. Most receptor proteins, to sense these stresses, are located in the plasma membrane and are directly involved in sensing external stimuli, aid effective regulation of plant-water relations (Zargar et al. 2017). Since both the stresses result in dehydration, though to a varying extent, many cellular responses (especially proteins) to drought and heat stress applied alone may be common, but differ when these stresses are present at the same time (Rizhsky et al. 2004; Zandalinas et al. 2018). Different transcription factors (TFs) have been reported

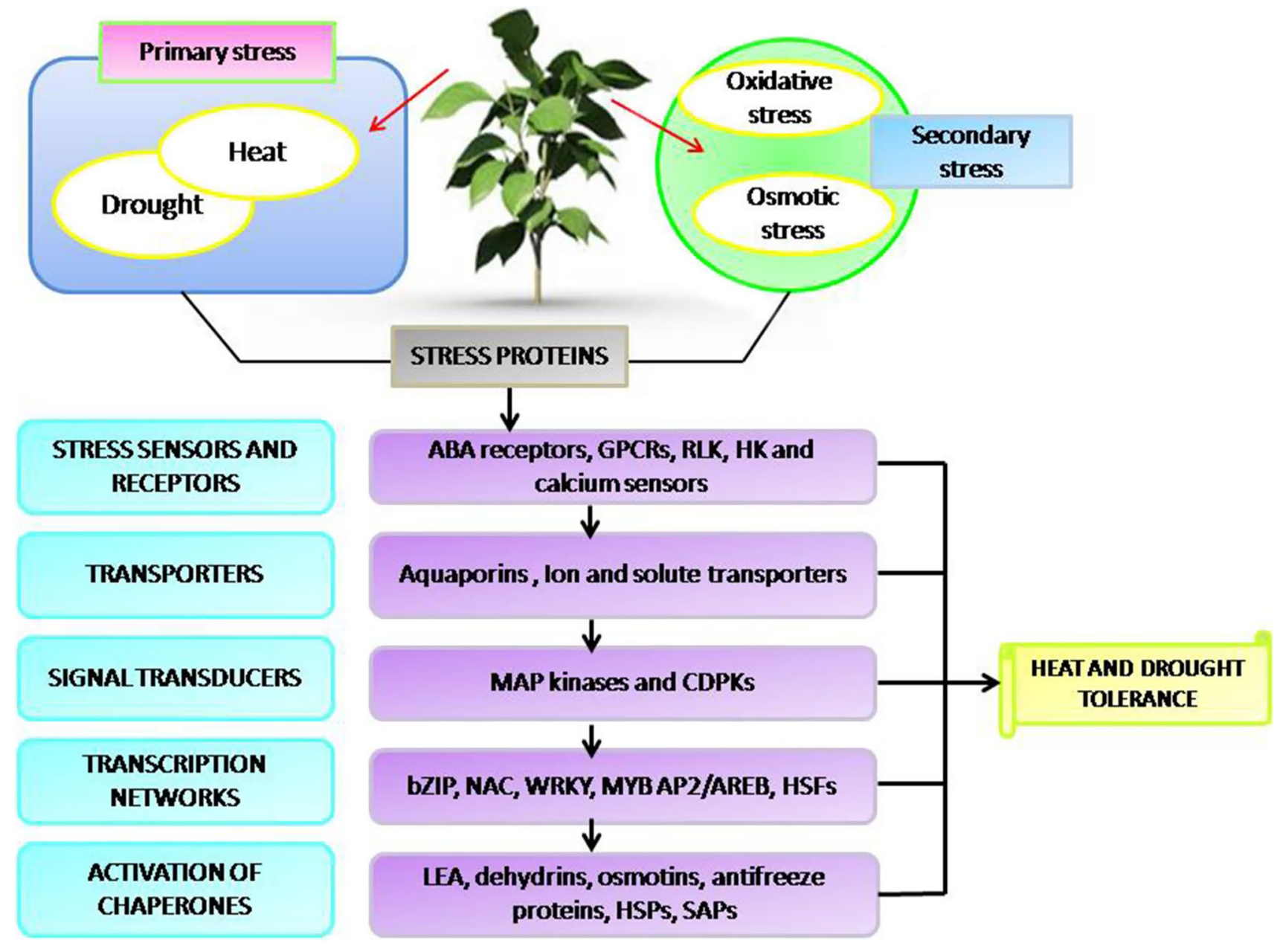

Fig. 1 In plants, abiotic stresses (heat or/and drought) are first sensed via membrane-localized stress sensors and receptors and the perceived stimulus is then relayed to intracellular compartments through secondary messengers especially calcium ions. Further, these calcium ions activate appropriate signaling pathways to transduce downstream signals. In all signaling pathways, MAPK (mitogen-activated pro- tein kinases) and CDPK (calcium-dependent protein kinases) act as potent signal transducers that initiate various transcription networks. The transcription factors regulate the transcription of different stressrelated proteins, which in turn act as chaperones to provide heat and drought tolerance as shown in figure 


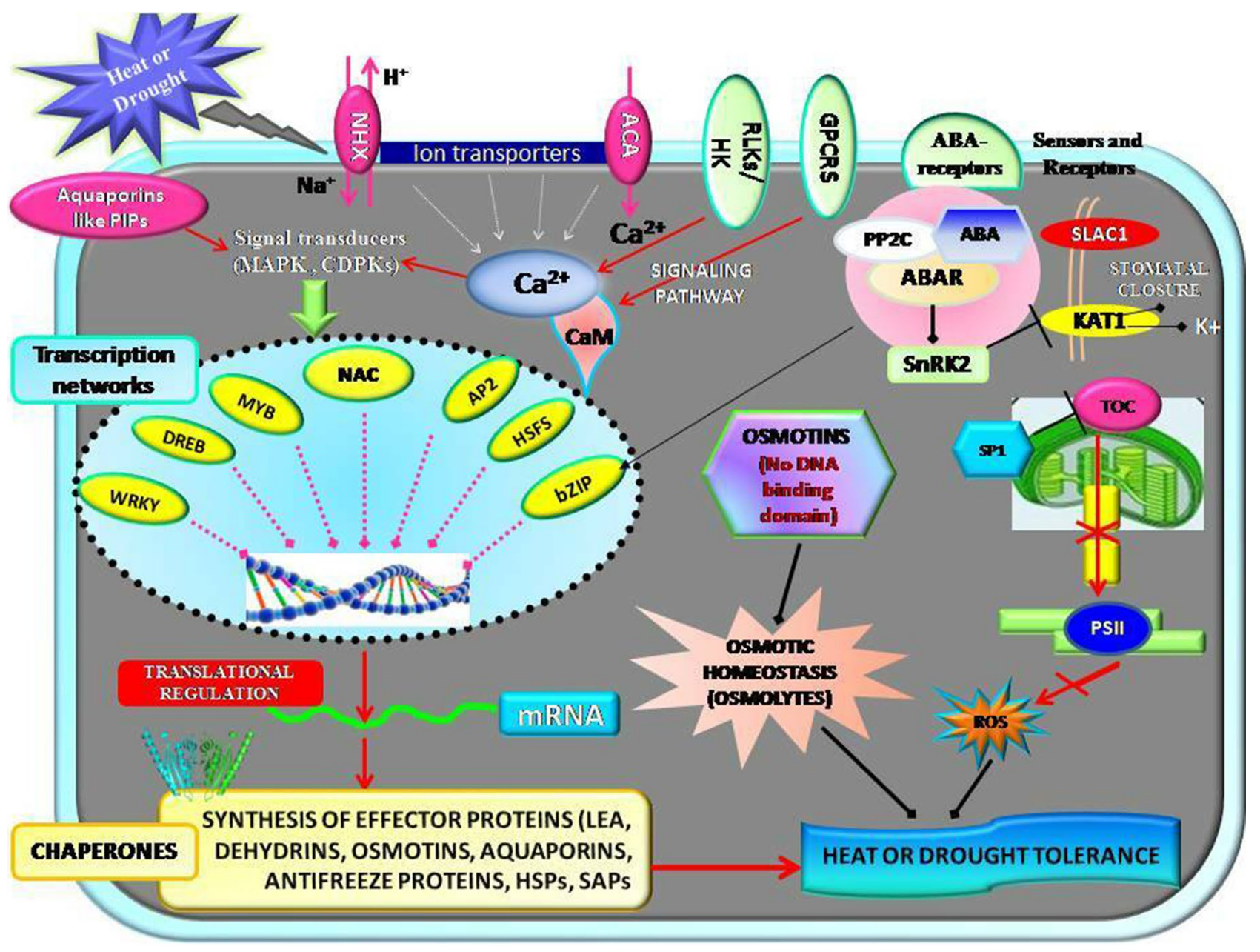

Fig. 2 Regulation of various stress-responsive proteins during heat and drought stress has been represented here. Drought or/and heat stresses were first detected by the sensors present in plasma membranes (GPCRs, RLKs, HK, ABA receptors, and calcium sensors) followed by transduction of information to appropriate effectors. ABA binds to PYR/PYL protein and forms a complex with PP2Cs, which covers the active sites of PP2Cs, thereby allowing autophosphorylation of SnRK2s. These phosphorylated SnRK2s participates in ABA-mediated stomatal closure via targeting NADPH oxidases and ion channels particularly SLAC1 (slow anion channel-associated 1) and KAT1 (potassium channel in Arabidopsis thaliana 1) in guard cell. The activated SLAC1 further causes membrane depolarization and opens external $\mathrm{K}^{+}$channels; the escape of $\mathrm{K}^{+}$and anions reduces guard cell's turgor and hence results in stomatal closure. The transporters (aquaporins, ion and solute transporters) shown in pink color activates calcium/calmodulin complex that plays an important role as a messenger or signal transducers. These calcium signals are generally decoded by protein kinases especially MAPK and CDPK that further initiate different transcription networks. Upregulated transcription factors such as WRKY, DREB, MYB, AP2, HSFs, and bZIP (upregulated by calcium and ABA) and NAC (upregulated by MAP kinases) bind to the specific DNA-binding promotor domain of stress-related genes and influence their transcription. After transcription, alternative splicing of newly synthesized mRNA leads to the formation of mature mRNA which is transported to the cytoplasm. In the cytoplasm, translated proteins are activated by phosphorylation or glycosylation and synthesize corresponding stress-responsive proteins, which provide drought or/and heat tolerance in plants. Osmotin is a multifunctional stress chaperone which lacks the DNAbinding domain and maintains osmotic homeostasis via accumulation of osmolytes (proline). SP1 a protein of the chloroplast membrane (ubiquitin-proteasome pathway) acts to destruct the TOC apparatus to restrict the import of photosynthetic apparatus (PS) components, which may debilitate photosynthetic activity and reduce reactive oxygen species (ROS) production and photo-oxidative damage. Broken arrows show possible but not firmly demonstrated paths. Abbreviations: PIP (plasma membrane intrinsic proteins), $\mathrm{NHX}\left(\mathrm{Na}^{2+} / \mathrm{H}^{+}\right.$ exchanger), ACA (calcium ATPases), RLKs (receptor-like kinases), GPCRs (G-protein-coupled receptors), PP2C (group-A protein phosphatases 2C), and SnRK2 (subclass III sucrose non-fermenting1 (SNF1)-related protein kinase 2), SLAC1 (slow anion channel-associated 1), KAT1 (potassium channel in Arabidopsis thaliana 1), MAPK (mitogen-activated protein kinases), CaM (calmodulins), WRKY (amino acid residues), DREB (dehydration-responsive element-binding protein), AP2 (apetala 2) (NAM, ATAF, and CUC transcription factors), HSFs (heat shock transcription factors), bZIP (basic leucine zippers), SP1 (chloroplast specificity protein), TOC (protein import machinery), PS (photosynthetic apparatus) 
to play crucial roles in coordination with receptors to control plant growth and developmental activities under stress situations (Wang et al. 2016b; Fig. 2). The protection to cells from dehydration is imparted by LEA (late embryogenesis-related proteins), osmotins, and dehydrins (Banerjee and Roychoudhury 2016). LEA proteins constitute a more widespread pool of proteins commonly termed 'hydrophillins' that defend other proteins from aggregation, desiccation, or osmotic stress (Ling et al. 2016). Likewise, osmotins are highly regulated proteins that protect cells from high osmolarity and structural or metabolic disruptions (Le et al. 2018). Under stressful conditions, (HSPs) or chaperones are upregulated to assist in folding, association, translocation, and degradation of proteins and hence stabilizing membranes and protein motifs (Ohama et al. 2017). These responses to prevailing stress factors are regulated by different and intermittently discrepant signaling cascades, which may have 'cross-talk' (Fahad et al. 2017). Hence, there is a need to unravel the underlying mechanisms that negotiate stress-sensing events protection and signal transduction pathways in drought and temperature-stressed plants (Zhu 2016). Recent proteomic techniques designed to interpret crop responses to abiotic stresses have emerged (Arbona et al. 2017), which are providing new insights about the diverse functional aspects of proteins in stressed plants.

Here, we provide an update on various stress (related) proteins (sensors, receptors, signals, and chaperones) that are expressed in response to adverse environmental conditions, with a focus on drought and heat stress, and how they confer protection and provide stability to plant cellular processes, considering the recent research advances in this area.

\section{Stress sensors and receptors}

Sensing environmental stimuli often involve some protein kinases and phosphatases, which regulate specific signaling cascades through the phosphorylation and dephosphorylation of specific proteins and the intensification of external impulses (Cristina et al. 2010). All these mechanisms eventually stimulate multiple defense actions and activate different developmental processes inclusive of cell enlargement and differentiation (Šamajová et al. 2013).

\section{G protein-coupled receptors (GPCRs)}

Environmental disturbances can trigger upregulation of some receptors present in the plasma membranes, which ultimately initiate downstream signaling circuits in an integrated and well-adopted manner (Osakabe et al.
2013). G protein-coupled receptors (GPCR) are plasma membrane-localized receptors that play crucial roles in plant abiotic stress responses (Choudhury et al. 2011); relatively less information is available about these proteins in plants. The existence of $\mathrm{G}$ protein-coupled receptors (GPCRs) in plants is still controversial; however, due to their significance in signaling, probing new GPCRs is necessary (Tuteja and Sopory 2008). The role of GPCR in stress sensing is significant as they perceive secondary signal relayed from abiotic stressors (Ullah et al. 2002; Fig. 2). By perceiving the adverse stimuli, the GPCRs communicate with associated $\mathrm{G}$ proteins that release GDP by binding GTP to the G $\alpha$ subunit (Choudhury et al. 2011). In Arabidopsis thaliana, single GPCR gene has been identified that was regulated by cell cycle and also participated in guard cell ABA signaling (Wang et al. 2001). The GPCR contains two highly conserved cysteine residues and a guanine nucleotide exchange factor (GEF) that further helps in GDP/GTP exchange (Yadav and Tuteja 2011). During abiotic stresses, G protein signaling pathways get activated, and $\mathrm{G}$ protein overexpressor plants have been found to show enhanced tolerance to heat stress as well as drought stress (Chen et al. 2003). Overexpression of RGS1 (Regulator of G protein Signaling1) provided drought resilience by upregulating the expression of genes involved in ABA biosynthesis (Misra et al. 2007). Targets of $G$ protein signaling in plants are very few; however, in Arabidopsis, putative effectors of G protein signaling pathway have been discovered (Chen et al. 2003). Few among them are related to animal proteins with well-known function in stress; however, their possible involvement in plants' abiotic stress responses is yet to be unveiled (Chen et al. 2003). The constitutive expression of $\mathrm{G} \alpha$ in transgenic tobacco plants enhanced tolerance to heat and salinity, whereas $\mathrm{G} \beta$-overexpression provided only heat resilience (Misra et al. 2007). From the above findings, it is evident that $\mathrm{G}$ proteins relay downstream signals on perceiving external stimuli, such as drought and heat, and impart cellular protection; however, these events are highly complicated and need future examination (Lu et al. 2018). Different studies showed the complex pathway of $\mathrm{G}$ protein regulated plant acclimation to different abiotic stresses (Urano and Jones 2014). Though multiple genetic studies have interpreted the role of $G$ proteins in stress sensing, the interaction of different downstream targets still needs to be probed during signaling events.

\section{Receptor-like protein kinases (RLKs)}

Since 1991, a detailed assay of protein kinase homolog P34 ${ }^{\text {cdc2 }}$ in Arabidopsis (Ferreira et al. 1991) has helped researchers to understand the functional aspects of protein kinases in plants. Notably, a special category of protein 
kinases, known as receptor-like kinases (RLKs), represents a significant protein group in plants, with 1132 and 610 RLKs recognized in rice and Arabidopsis, respectively (Shiu et al. 2004). RLKs represent a highly conserved serine-/threonine-linked signaling module that monitors all developmental events in plants along with hormone perception and homeostatic mechanisms covering abiotic stress responses (Osakabe et al. 2013). Most RLKs are plasma membrane-localized proteins; however, a few are specifically restricted to other places, for instance, apoplastic rice root meander curling (OsRMC) kinases, cytoplasmic-RLKs situated in cytoplasm (Zhang et al. 2014), and wall-associated kinases knitted to the pectin fragment of the cell wall (Lim et al. 2015). According to Greeff et al. (2012), a model RLK protein encompasses a transmembrane domain (TM), an external ligand-binding domain (ECLB), and a protein kinase catalytic domain (PKC). A PKC is the major intermediary of signaling events responsible for activation or repression of target genes (Zou et al. 2014). In rice, a floral organ number 1, (FON1), gene has been identified as LRR-RLK, which can be induced by drought stress (Feng et al. 2014). Similarly, in Arabidopsis, 'FERONIA' receptor kinases protect cell wall against drought-induced damages (Feng et al. 2018). Further, an Arabidopsis ortholog of the wheat LRK10 gene serves as beneficial feedback in drought resistance by stomatal closure, involving ABA-dependent signaling pathways (Lim et al. 2015). The marked expression behavior of an OsNRRB RLK in rice (Oryza sativa) encoding OsNRRB protein has been determined, and a transcriptomic assay showed that hybrid plants overexpressing the OsNRRB gene exhibit exceptionally higher resilience to water deficit (Zhang and Chen 2017). Moreover, the upregulation of A. thaliana receptor-like kinase 'ERECTA' (ER) in transmutant tomato and rice imparted heat tolerance irrelevant to water loss (Shen et al. 2015), which could be used in breeding programs to develop thermo-tolerant varieties. A wide range of RLKs have been isolated from different plant species; however, in contrast to animal protein kinases, the study of RLKs in plants is more recent (Ye et al. 2017). Extensive research is needed to spotlight the roles of RLKs in associated signaling networks throughout the process of abiotic stress responses.

\section{Histidine kinases}

In plants, histidine kinases (HK) have been identified in large variety of crop plants and act as primary signaling component governing a bulk of responses, especially stress sensing (Singh et al. 2015). Signal received by histidine kinases is relayed downstream through transfer of phosphate group to some other signal transducers and finally to respond regulators (Nongpiur et al. 2012), described as TCS ("two-component system") (Osakabe et al. 2013). Currently, several histidine kinases have been also explored to mediate drought stress responses in Arabidopsis (Kumar et al. 2013). Eight HK members were identified in Arabidopsis, among which five (ERS1, ETR1, AHK2, AHK3, and AHK4) are involved in perceiving two plant hormones, i.e., ethylene and cytokinin (Schaller et al. 2008). Apart from hormonal HK, function of non-hormonal HKs (AHK1, AHK5, and CKI1) was also studied thoroughly; AHK1 was recognized as a novel osmosensor regulating osmotic stress response (Tran et al. 2007; Wohlbach et al. 2008). In Arabidopsis, upregulation of AHK1 enhances tolerance to osmotic stress, whereas the AHK1 knockout mutants were highly susceptible to osmotic stress (Tran et al. 2007; Wohlbach et al. 2008). AtHK1 has been also reported to regulate drought stress responses in Arabidopsis and was expressed highly in roots than other tissues (Wohlbach et al. 2008). The mutants for AHK1 were less sensitive to ABA, showing AHK1 as a potential osmosensor regulating osmotic stress signaling and expression of effector genes in both an ABA-dependent and ABA-independent manner (Tran et al. 2007; Wohlbach et al. 2008). In maize, expression of three histidine kinases, i.e., ZmHK1, ZmHK2, ZmHK3a, was analyzed during drought and UV B-radiations' exposure (Susan et al. 2013). ZmHKI and $Z m H K 3 a$ transcripts were upregulated during these stresses, suggesting $\mathrm{ZmHKI}$ and $\mathrm{ZmHK3a}$ as putative osmosensors as well as cytokinin receptors that sense osmotic changes induced by dehydration stress (Susan et al. 2013). A plasma membrane-localized $A H K 5$ that regulates stomatal closure in response to increased ROS, especially $\mathrm{H}_{2} \mathrm{O}_{2}$, was identified (Desikan et al. 2008); however, in AHK5 mutants, reduced ROS sensitivity and stomatal closure have been observed. Histidine-aspartate phosphotransfer system, functioning downstream to HKs, has been reported to regulate various abiotic stress responses, including drought, heat, cold, and salinity (Ha et al. 2012; Pham et al. 2012). Overall, above reports suggested that cross-talk between stress sensing and signaling networks plays essential roles in plant stress response. Further, genome editing of these kinases through emerging technologies may help to understand how they regulate downstream signaling networks during stresses conditions.

\section{$A B A$ receptors}

One of the earliest responses to stresses such as drought and heat involves the synthesis of a phytohormone-abscisic acid (ABA) (Yamaguchi-Shinozaki and Shinozaki 2006) that regulates various plant growth and developmental programmes and also acts as an endogenous messenger in response to diverse environmental cues (Hines 2009). ABA produced in the cells is sensed by cytosolic calcium ions that further activates two types of anion channels, i.e., slow type and rapid type, which result in 
stomatal closing involving expression of some proteins such as CPK10, CPK21 (calcium-dependent protein kinases), $\mathrm{ABH} 1$ (nuclear cap-binding protein involved in ABA signaling), ALMT12 (anion transporter for stomatal closure), etc. (Daszkowska-Golec and Szarejko 2013). Abiotic stresses, mainly drought, cause cellular dehydration in plants, which increases ABA content in vascular tissues as well as transport to sites of ABA action (Nambara and Marion-Poll 2005). A significant progress in the identification of ABA-responsive genes has been made; however, the detailed insight of ABA perception by the plant cell is still elusive (Kline et al. 2010). In 2009, discovery of chief ABA signaling components and the identification of START domain proteins PYR/PYL/RCAR as ABA receptors (ABAR) provided knowledge regarding molecular aspects of ABA signaling (Ma et al. 2009; Park et al. 2009). Major signaling components include ABAR (initially known as PYRABACTIN RESISTANCE [PYR]/ PYR1-LIKE [PYL], which belongs to START protein superfamily, group-A protein phosphatases 2C (PP2C), and subclass III sucrose non-fermenting1 (SNF1)-related protein kinase 2 (SnRK2, also named SRK2) (Dalal and Chinnusamy 2015). Stress-induced increase in cellular ABA is first recognized by the START domain of PYL/ RCAR (pyrabactin resistance-like/regulatory) component of ABA receptors protein family (Ma et al. 2009). ABA binds to PYR/PYL protein and forms a complex with PP2Cs, which covers the active sites of PP2Cs, thereby allowing autophosphorylation of SnRK2s (Joshi-saha et al. 2011). These phosphorylated SnRK2s participate in ABA-mediated stomatal closure via targeting NADPH oxidases and ion channels particularly SLAC1 (slow anion channel-associated 1) (Geiger et al. 2009; Vahisalu et al. 2010) and KAT1 (potassium channel in Arabidopsis thaliana 1) (Sato et al. 2009) in guard cell. The activated SLAC1 further causes membrane depolarization and opens external $\mathrm{K}^{+}$channels, and the escape of $\mathrm{K}^{+}$ and anions reduces guard cell's turgor and hence results in stomatal closure (Geiger et al. 2009; Lee et al. 2009). Apart from this, SnRK2s are also involved in ABAinduced transcriptional regulation via activating basic leucine zipper (bZIP) transcription factors (TFs), ABAresponsive element (ABRE) binding factor, and ABAINSENSITIVE 5 (ABI5) (Yoshida et al. 2010). Some other known ABA-binding receptor proteins include plasma membrane-localized GPCR2 (G protein-coupled receptors), GTG1/GTG2 (G protein-coupled receptor-type G proteins), FCA, CHLH and GCR2; however, none has been further substantiated (Miyakawa et al. 2013). By knowing the roles and signaling mechanisms of the crucial targets in the core ABA pathways, ABA perception could be enhanced via engineering transgenic lines overexpressing ABA effectors ( $\mathrm{Ng} 2016$ ). The biological role of different PYLs in conferring abiotic stress tolerance has been recently illustrated by several researchers. For instance, overexpression of PYL13 results in increased ABA sensitivity as well as drought tolerance in Arabidopsis (Zhao et al. 2013a, b). Shi et al. (2014) also observed enhanced expression of AtPYL4 and AtPYL5 in Arabidopsis thaliana that increases antioxidant activity, osmolyte accumulation, and drought resistance in transgenic lines. Similar findings have been obtained in rice (Oryza sativa), where increased expression of $O S P Y L$ (the rice ortholog of Arabidopsis PYL), enhanced dehydration, and heat tolerance (Kim et al. 2014). Tian et al. (2015) characterized a PYLs protein in rice cultivar Oryza sativa L. ssp japonica cv. Nipponbare and the upregulation of OsPYL/RCAR 5 provided enhanced tolerance to drought stress. The study of Zhao et al. (2016) showed that in transgenic Arabidopsis, PYL9 not only prevents transpirational water loss under severe drought, but also induces some summer dormancy-like responses such as growth inhibition in young parts and senescence in old leaves. Similarly, in poplar genome (Populus trichocarpa), 14 PYR/PYL/RCAR orthologs were encoded (PtPYRLs) and two among them, i.e., PtPYRL1 and PtPYRL5, have been characterized extensively to regulate drought responses (Yu et al. 2017). The constitutive expression of PtPYRL1 and PtPYRL5 increases tolerance to drought and high osmolarity in 'poplar' by regulating ABA signaling (Yu et al. 2017). The upregulation of OSPYL3 in droughtresistant rice variety, Nagina22 (N22), imparted multiple abiotic stress tolerance in transgenic plants (Lenka et al. 2018). In maize also, 13 PYLs (ZmPYLs 1-13) were identified and changes in their expression under diverse abiotic stresses showed that they may act as potential candidates for breeding stress-tolerant maize cultivars (He et al. 2018). Moreover, ABA also initiates different signaling cascades involving LEA (late embryogenesis abundant) class genes and other regulatory genes necessary for plants acclimation to drought and heat stress (Suzuki 2016).

As mentioned above, ABA is a key signaling compound that can relay signals sensed during diverse environmental stresses, and further examination of $\mathrm{ABA}$ receptors and ABA-responsive genes may provide deep insight of functional aspects of ABA under combination of stresses ( $\mathrm{Ng} \mathrm{2016).} \mathrm{Although} \mathrm{a} \mathrm{large} \mathrm{number} \mathrm{of} \mathrm{stud-}$ ies showed valuable information at the elementary stage, future testing in field crops is required to examine their agricultural practicability.

\section{Calcium sensors}

Signals sensed by the stressed cells are conveyed by secondary messengers, such as $\mathrm{Ca}^{2+}$ ions, cAMP, cGMP, $\mathrm{IP}_{3}$, 
and other small hydrophilic molecules. The functional aspects of $\mathrm{Ca}^{2+}$ have been examined widely in cells facing drought (Zhu 2002) and heat stress (Goswami et al. 2015). Plants recruit calcium $\left(\mathrm{Ca}^{2+}\right)$ ions as an accessory mediators in communicating external (environmental) and internal (developmental) cues to associable cellular and genetic responses (Kudla et al. 2010; Fig. 2). This is apparent from evidences that virtually all cues (hormonal, developmental and stresses) induce a shift in cytosolic $\mathrm{Ca}^{2+}$ and, in a few cases, in the nucleus and other cell inclusions (Reddy et al. 2011). The spatiotemporal $\mathrm{Ca}^{2+}$ rise along with the periodicity and magnitude of $\mathrm{Ca}^{2+}$ oscillations regulates different signals including environmental stress responses (Zeng et al. 2015). The fluctuations in cytosolic $\mathrm{Ca}^{2+}$ levels are deciphered by an array of $\mathrm{Ca}^{2+}$ sensor proteins that encompass a homologous $\mathrm{Ca}^{2+}$-binding domain, the 'EF-hand' domain (Ranty et al. 2016).

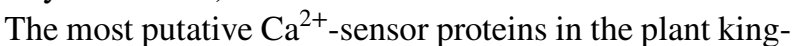
dom are (1) calcium-regulating proteins or calmodulins (CaM), (2) calmodulin-like proteins (CML), (3) calcineurin B-like proteins, and (4) $\mathrm{Ca}^{2+}$-dependent protein kinases (CDPKs) (Rasul et al. 2017). The widespread effects of $\mathrm{Ca}^{2+}$ are generally derived from the calmodulin subclass of $\mathrm{Ca}^{2+}$ sensor proteins (Virdi et al. 2015).

Calmodulin $(\mathrm{CaM})$ is an extensively characterized, highly conserved $\mathrm{Ca}^{2+}$ sensor protein found in all eukaryotes, which plays an important role in $\mathrm{Ca}^{2+}$-mediated signaling in response to numerous cellular processes (Zhu et al. 2015). It has been speculated that communication between $\mathrm{Ca}^{2+}-\mathrm{CaM}$ and terminal proteins results in marked intensification of $\mathrm{Ca}^{2+}$ spikes, thus imparting high resilience to cells when decoding distinct $\mathrm{Ca}^{2+}$ responses for altering gene expression (Zhao et al. 2013a, b). Proleptical transcriptomic studies showed that nearly all calmodulin and calmodulinlike genes in A. thaliana are highly "stress responsive" in $\mathrm{Ca}^{2+}$-mediated stress signaling (Perochon et al. 2011). Their roles in stress tolerance were validated involving transgenic studies. For example, a putative calmodulin-like (ShCML44) gene isolated from a cold-resilient variety of wild tomato (Solanum habrochaites) conferred enhanced resilience to drought conditions in transmutant lines (Munir et al. 2016). Similarly, a novel CML multi-stress-responsive gene 2, OSMSR2, from rice imparts drought stress resilience in plants via ABA-mediated signaling in transgenic Arabidopsis (Xu et al. 2011). A CML, OsDSR-1 (Oryza sativa Drought Stress Response-1), was also characterized by Yin et al. (2017), and transgenic plants overexpressing OsDSR-1 showed more drought tolerance as well as ABA sensitivity. Similarly, Qiao et al. (2015) elucidated the possible role of annexins (ANN1, a calcium binding protein) in conferring abiotic stress resilience in rice; enhanced expression of OSANN, provided high tolerance to heat stress by promoting the activities of catalase and superoxide dismutase, which regulates ROS production. Considering above facts, emphasis should be given on studying the CaM-regulated activation of target proteins to further understand the role of $\mathrm{CaMs}$ in drought and heat stress tolerance.

\section{Calcineurin B: like proteins}

During adverse stress conditions, a class of $\mathrm{Ca}^{2+}$ sensors, calcineurin B-like proteins (CBL), and their equivalent kinase targets-CBL-interacting protein kinases (CIPK) act as primary components in signaling events associated with $\mathrm{Ca}^{2+}$ sensors, which is termed the CIPK/CBL cascade (Yu et al. 2014). The CIPK-CBL pathway controls various downstream effectors including ion carriers and transporters (Manik et al. 2015) and performs different roles in abiotic stress resilience. The cytosolic rise in $\mathrm{Ca}^{2+}$ ions owing to alterations in the external environment leads to $\mathrm{CBL}$ binding with $\mathrm{Ca}^{2+}$ to form a CBL-CIPK type complex, which is responsible for decoding $\mathrm{Ca}^{2+}$ signatures (Zhu et al. 2015). CBLs communicate with a set of protein kinases known as CBL-interacting protein kinases or SnRK3s (sucrose non-fermenting-1 related kinases) through the CIPK-NAF domain (Chen et al. 2012). This interaction ultimately causes phosphorylation of the ensuing effector proteins that help to improve stress tolerance (Hashimoto et al. 2012). Previous data revealed that CIPK3 transcripts were highly upregulated during drought and ABA stress, and the interruption of CIPK3 impaired the expression behavior of numerous stress marker genes during acclimation responses to abiotic stresses. (Kim et al. 2003). The overexpression of $O s C B L 8$ (Oryza sativa) increased drought stress tolerance in transgenic rice plants ( $\mathrm{Gu}$ et al. 2008). Comprehensive research in the field of 'omics' has provided beneficial results regarding calcium signaling, but, so far, little information is available on the transduction of $\mathrm{Ca}^{2+}$ signals into high-throughput physiological responses (Simeunovic et al. 2016). The recently discovered calcium sensor, i.e., calcineurin B-like proteins (CBLs), and their interacting partners CBL-interacting protein kinases (CIPKs) have emerged as key network that plays an important role in abiotic stress signaling in plants (Manik et al. 2015). Different CBLs and their associated protein kinases function in stomatal closure, ion homeostasis, ROS scavenging, osmolyte biosynthesis, and transcriptional regulation of stress-related genes and hence may act as crucial regulator of drought and salt stress tolerance (Luo et al. 2017).

\section{Transporter proteins}

\section{Water channel proteins or aquaporins}

Aquaporins are crucial regulators of plant-water homeostasis and are the choice of target proteins for developing 
stress resilient plants (Maurel et al. 2015). The potential of AQPs for combating environmental hazards has been implicated by the expression of aquaporin isoforms, which are differentially regulated by environmental stresses, such as high salinity, drought, and cold (Xu et al. 2013). They are highly conserved membrane channels, which intensify water permeability in cell membrane systems during stressful conditions, thus maintaining cellular homeostasis by preventing water loss (Xu et al. 2013; Fig. 2). In plants, AQPs are emerging as vital players in sustaining the physiology of water-use efficacy, plant growth, and responses to external signals (Maurel et al. 2015). They act as vital nodes in coordinating cell metabolism and signaling at the whole plant level, mainly by interacting with ROS in response to extrinsic signals (Deshmukh et al. 2016). As integral channel proteins, they assist in the transport of small neutral molecules such as water and glycerol, along with volatile substances like $\mathrm{CO}_{2}$, nitric oxide (NO), or $\mathrm{NH}_{3}$ across biological membranes (Kaldenhoff and Fischer 2006). Aquaporins belong to a highly diverse major intrinsic protein family (MIP), which has five distinct groups based on subcellular location and sequence similarities (Park and Campbell 2015): plasma membrane intrinsic proteins (PIPs; Fig. 2), nodulin 26-like intrinsic proteins (NIPs), tonoplast intrinsic proteins (TIPs), small intrinsic proteins (SIPs), and uncharacterized $\mathrm{X}$ intrinsic proteins (XIPs) (Chaumont and Tyerman 2014). PIPs and TIPs are highly expressed in the plasma membrane and tonoplast (vacuolar membrane), respectively, whereas NOD26 (NIPs) initially targeted the peri-bacteroid membrane in root nodules of legume plants ( $\mathrm{Li}$ et al. 2014a). NIPs are also present in non-leguminous plants and localized on the plasma membrane. The functional aspects of SIPs and (XIPs) in plants are yet to be determined. The role of TIPs in water transportation has been reported in the expression of Arabidopsis homologs, AtTIP1;1 AtTIP1;2, and AtTIP2;3 expression in yeast (Wang et al. 2016a), and the activities of aquaporins have been described in diverse wild or cultivated, herbaceous, or woody plant species (Deshmukh et al. 2016).

Remarkable progress has been made in interpreting the useful role of PIPs as they constitute one of the major subfamilies in AQPs. While numerous studies have revealed that overexpression of specific PIP genes is favorable under stress situations, the functional aspects of PIPs remain largely unknown (Javot and Maurel 2002). Likewise, TIPs are a group of plant aquaporins involved in monitoring osmotic stress responses and water exchange between cytosolic and vacuolar membranes (Shao et al. 2009). The expression of aquaporins is altered in response to drought stress and has been linked to affect the water status. For instance, drought-induced expression of certain CsPIPs from Camellia sinensis remained comparatively high after rehydration in leaves (Yue et al. 2014). Similarly, the highly expressed lily PIP1 gene in tobacco enhanced water permeability as well as the conductivity of leaf protoplasm including leaf cells (Ding et al. 2004). A model of cell osmotic adjustment involving stress-activated $\mathrm{Ca}^{2+}$ channel and SoPIP2;1 from Spinacia oleracea was designed to explain aquaporin phosphorylation in relation to cellular hydraulic conductivity, which helps to increase water potential to support the passage of water in fully turgid cells (Maurel et al. 2008). In a few cases, the scarcity of PIP2 proteins under water deficit has been observed, but a noticeable aggregation of PIP1 proteins was reported (Aharon et al. 2003). There are several examples where the expression of aquaporins has been altered resulting in varied results in transgenic plants (Table 1).

Due to their significant contribution to water stress tolerance, aquaporins may act as tangible candidates for improving agricultural productivity in a stressful open environment (Laur and Hacke 2014). Further in-depth studies are needed to find out their regulatory and functional aspects, under drought and heat stress, environments, especially under stress combination.

\section{Signal transducers}

\section{MAP kinases}

The mitogen-activated protein kinase (MAPK) cascade is a class of protein kinases that regularly participates in cellular organization or gene expression of eukaryotic organisms including plants (Ning et al. 2010). MAPKs are a signaling link in the perception of external signals and management of diverse physiological and developmental processes (Joshi et al. 2011). All living plant cells are highly efficient in sensing stresses via distinct sensors present in cell membranes and driving them downstream using the MAPK cascade (Sinha and Ara 2014). A MAPK cascade usually comprises a MAPKKK-MAPKK-MAPK moiety that is associated with upstream signaling receptors and specific downstream targets, which are switched on in a chronological order through phosphorylation (Danquah et al. 2014). Advancements in genome sequencing have revealed that MAPKs are an integral part of plant signal transduction pathways related to drought, as well as heat stress (Moustafa et al. 2014; Berriri et al. 2012). In the Arabidopsis genome, more than 20 MAPKs, 10 MAP2Ks, and 80 MAP3Ks have been characterized of which three MAPKs, i.e., MPK6, MPK4 and, MPK3, have been extensively studied (de Zelicourt et al. 2016). MAP kinases, along with phosphatases, generally act as off/on signal activators to control the action of multiple cytosolic proteins or nuclear transcription factors to regulate cell signaling as well as plant acclimation to climatic 
Table 1 Transgenics developed through over/under-expression of stress-related proteins

\begin{tabular}{|c|c|c|c|c|}
\hline Stress protein transgene & Source plant & Target plant & Physiological function & References \\
\hline \multicolumn{5}{|l|}{ Stress sensors } \\
\hline \multicolumn{5}{|c|}{ Receptor-like kinases (RLKs) } \\
\hline OsNRRB & Oryza sativa (rice) & Rice & $\begin{array}{l}\text { High tolerance to drought, } \\
\text { and oxidative stress }\end{array}$ & Zhang and Chen (2017) \\
\hline OsLRR2 & Oryza sativa (rice) & Rice & $\begin{array}{l}\text { Enhanced tolerance to heat, } \\
\text { drought and cold stress }\end{array}$ & Liao et al. (2017) \\
\hline \multicolumn{5}{|l|}{ Calcium sensors } \\
\hline GhCIPK6 & Gossypium hirsutum (cotton) & Arabidopsis & $\begin{array}{l}\text { Provides resistance to } \\
\text { drought and ABA }\end{array}$ & He et al. (2013) \\
\hline VaCPK20 & Vitis amurensis (Grapevine) & Arabidopsis & $\begin{array}{l}\text { Transgenic plants showed } \\
\text { enhanced resilience to } \\
\text { drought stress }\end{array}$ & Dubrovina et al. (2015) \\
\hline OsANN1 & Oryza sativa (rice) & Rice & $\begin{array}{l}\text { Improves heat stress toler- } \\
\text { ance by modulating ROS } \\
\text { production }\end{array}$ & Qiao et al. (2015) \\
\hline \multicolumn{5}{|l|}{ Transporters } \\
\hline \multicolumn{5}{|l|}{ Aquaporins } \\
\hline CsTIP4;1-1 & Camellia sinensis (tea plant) & Camellia & $\begin{array}{l}\text { Drought resistance in trans- } \\
\text { genic lines, high antioxi- } \\
\text { dant activity }\end{array}$ & Yue et al. (2014) \\
\hline CsTIP2;1 & Citrus spp. & Tobacco & $\begin{array}{l}\text { Increased cell expansion, } \\
\mathrm{H}_{2} \mathrm{O}_{2} \text { detoxification and } \\
\text { under drought stress }\end{array}$ & Martins et al. (2017) \\
\hline BnPIP & Brassica napus (mustard) & Tobacco and rice & $\begin{array}{l}\text { High tolerance to drought } \\
\text { and high hydraulic con- } \\
\text { ductivity }\end{array}$ & Maurel et al. (2008) \\
\hline SITIP2;3 & $\begin{array}{l}\text { Solanum lycopersicon } \\
\quad \text { (tomato) }\end{array}$ & Tomato & $\begin{array}{l}\text { Maintain water or solute } \\
\text { homeostasis and entire } \\
\text { plant transpiration }\end{array}$ & Reuscher et al. (2013) \\
\hline MaPIP1;1 & Musa acuminata (banana) & Arabidopsis & $\begin{array}{l}\text { Regulate water-use effi- } \\
\text { ciency and hydraulic con- } \\
\text { ductivity during drought } \\
\text { stress }\end{array}$ & Xu et al. (2014b) \\
\hline VzPIP1;1 & Vetiveria zizaniodes (vetiver) & Soybean & $\begin{array}{l}\text { Better photosynthetic activ- } \\
\text { ity and root water transport } \\
\text { under water stress }\end{array}$ & Hu et al. (2016a) \\
\hline MdPIP1;3 & Malus domestica & Tomato & Drought resistance & Wang et al. (2017b) \\
\hline \multicolumn{5}{|l|}{ Signal transducers } \\
\hline \multicolumn{5}{|l|}{ MAP kinases } \\
\hline MnMAPK1 & Morus nigra (mulberry) & Arabidopsis & $\begin{array}{l}\text { Improved resilience to } \\
\text { drought, salt, and } \mathrm{H}_{2} \mathrm{O}_{2} \\
\text { stress }\end{array}$ & Liu et al. (2017) \\
\hline ZmMAPK1 & Zea mays (maize) & Arabidopsis & $\begin{array}{l}\text { Enhanced resistance to } \\
\text { drought and heat stress }\end{array}$ & Wu et al. (2015) \\
\hline \multicolumn{5}{|l|}{ Transcription factors } \\
\hline \multicolumn{5}{|c|}{ Basic leucine zippers (bZIP) } \\
\hline ABP9 & Zea mays (maize) & Cotton & $\begin{array}{l}\text { Overexpressors showed low } \\
\text { MDA content and reduced } \\
\text { level of ROS during } \\
\text { drought conditions }\end{array}$ & Wang et al. (2017a) \\
\hline VqbZIP39 & $\begin{array}{l}\text { Vitis quinquangularis (tree } \\
\text { vine) }\end{array}$ & Arabidopsis & $\begin{array}{l}\text { Enhanced seed germination } \\
\text { and seedling growth dur- } \\
\text { ing drought and oxidative } \\
\text { stress }\end{array}$ & Tu et al. (2016) \\
\hline
\end{tabular}


Table 1 (continued)

\begin{tabular}{|c|c|c|c|c|}
\hline Stress protein transgene & Source plant & Target plant & Physiological function & References \\
\hline \multicolumn{5}{|l|}{ NAC transcription factors } \\
\hline ThNAC13 & $\begin{array}{l}\text { Tamarix hispida (kashgar } \\
\text { tree) }\end{array}$ & Tamarix and arabidopsis & $\begin{array}{l}\text { Increased drought and } \\
\text { osmotic stress tolerance }\end{array}$ & Wang et al. (2017d) \\
\hline $\begin{array}{l}\text { PeNAC034 } \\
\text { PeNAC045 } \\
\text { PeNAX036 }\end{array}$ & Populus euphratica (poplar) & Arabidopsis & $\begin{array}{l}\text { High survival rate and } \\
\text { reduced water loss under } \\
\text { drought stress }\end{array}$ & Lu et al. (2017) \\
\hline AtJUB1 & $\begin{array}{l}\text { Arabidopsis thaliana (Arabi- } \\
\text { dopsis) }\end{array}$ & Tomato & $\begin{array}{l}\text { Increased antioxidant activ- } \\
\text { ity and lower MDA content } \\
\text { under drought and salt } \\
\text { stress }\end{array}$ & Thirumalaikumar et al. (2017) \\
\hline \multicolumn{5}{|c|}{ WRKY transcription factors } \\
\hline DgWRKY5 & $\begin{array}{l}\text { Dendranthema grandiflora } \\
\text { (chrysanthemum) }\end{array}$ & Chrysanthemum & $\begin{array}{l}\text { High antioxidant activity } \\
\text { and proline accumulation, } \\
\text { improved yield potential } \\
\text { under drought stress }\end{array}$ & Liang et al. (2017) \\
\hline GsWRKY20 & Glycine soja (soybean) & Soybean & $\begin{array}{l}\text { High proline accumulation, } \\
\text { low MDA, and increased } \\
\text { antioxidant activity in } \\
\text { transgenic }\end{array}$ & Ning et al. (2017) \\
\hline \multicolumn{5}{|l|}{ MYB transcription factors } \\
\hline TaODORANT1 & Triticum aestivum (wheat) & Tobacco & $\begin{array}{l}\text { Higher catalase activity, } \\
\text { MDA and } \mathrm{H}_{2} \mathrm{O}_{2} \text { content } \\
\text { under stress }\end{array}$ & Wei et al. (2017) \\
\hline FtMYB10 & $\begin{array}{l}\text { Fagopyrum tataricum (buck- } \\
\text { wheat) }\end{array}$ & Arabidopsis & $\begin{array}{l}\text { Enhanced tolerance to } \\
\text { drought stress }\end{array}$ & Gao et al. (2016) \\
\hline \multicolumn{5}{|c|}{ AP2/ERBP transcription factors } \\
\hline ThDREB & $\begin{array}{l}\text { Tamarix hispida (kashgar } \\
\text { tree) }\end{array}$ & Tobacco & $\begin{array}{l}\text { Transgenics show high } \\
\text { germination rates, fresh } \\
\text { weights and root lengths }\end{array}$ & Yang et al. (2017) \\
\hline AaDREB1 & Adonis amurensis (amur) & Arabidopsis and rice & $\begin{array}{l}\text { Enhanced tolerance to } \\
\text { drought and high-tempera- } \\
\text { ture stress }\end{array}$ & Zong et al. (2016) \\
\hline \multicolumn{5}{|l|}{ Chaperones } \\
\hline \multicolumn{5}{|l|}{ LEA and dehydrins } \\
\hline WRAB18 & Triticum aestivum (wheat) & Tobacco and $E$ coli & $\begin{array}{l}\text { Reduced malondialdehyde } \\
\text { levels and increased } \\
\text { antioxidant activity in } \\
\text { transgenic lines }\end{array}$ & Wang et al. (2017d) \\
\hline OsLEA4 & Oryza sativa (rice) & Rice & $\begin{array}{l}\text { Increased resistance to } \\
\text { drought stress }\end{array}$ & Hu et al. (2016b) \\
\hline \multicolumn{5}{|l|}{ Osmotins } \\
\hline SindOLP & Nicotiana tobacum (tobacco) & Sesame & $\begin{array}{l}\text { Less electrolyte leakage, } \\
\text { longer roots, increased } \\
\text { chlorophyll, and proline } \\
\text { content under drought } \\
\text { stress }\end{array}$ & Chowdhury et al. (2017) \\
\hline Osmotin gene & Olea europea (olive) & Olive & $\begin{array}{l}\text { Enhanced accumulation of } \\
\text { osmolytes and increased } \\
\text { activity of antioxidant } \\
\text { enzymes }\end{array}$ & Silvestri et al. (2017) \\
\hline \multicolumn{5}{|l|}{ Antifreeze proteins } \\
\hline LpAFP & Lolium perenne (ryegrass) & Arabidopsis & $\begin{array}{l}\text { Transgenic plants showed } \\
\text { reduced electrolyte leakage }\end{array}$ & Bredow et al. (2017) \\
\hline AnAFP & Ammopiptanthus nanus & Tobacco & $\begin{array}{l}\text { Reduction in membrane } \\
\text { damage and enhanced } \\
\text { tolerance to heat stress }\end{array}$ & Deng et al. (2014) \\
\hline
\end{tabular}


Table 1 (continued)

\begin{tabular}{|c|c|c|c|c|}
\hline Stress protein transgene & Source plant & Target plant & Physiological function & References \\
\hline \multicolumn{5}{|l|}{ Heat shock proteins } \\
\hline MsHsp23 & Medicago sativa (alfalfa) & Alfalfa & $\begin{array}{l}\text { Enhanced tolerance to heat } \\
\text { and oxidative stress }\end{array}$ & Lee et al. (2017) \\
\hline LlHsfA2B & Lilium longiflorum (lily) & Arabidopsis & $\begin{array}{l}\text { Increased heat tolerance } \\
\text { through upregulation of } \\
\text { antioxidant and chaperon- } \\
\text { ing machinery }\end{array}$ & Xin et al. (2017) \\
\hline MuHSP70 & $\begin{array}{l}\text { Macrotyloma uniflorum } \\
\text { (horse gram) }\end{array}$ & Arabidopsis & $\begin{array}{l}\text { Enhanced tolerance to heat, } \\
\text { drought, and oxidative } \\
\text { stress }\end{array}$ & Masand and Yadav (2016) \\
\hline BcHSP70 & $\begin{array}{l}\text { Brassica compestris (mus- } \\
\quad \text { tard) }\end{array}$ & Tobacco & $\begin{array}{l}\text { Accumulation of osmolytes } \\
\text { and decreased MDA } \\
\text { content under heat stress } \\
\text { conditions }\end{array}$ & Wang et al. (2016c) \\
\hline
\end{tabular}

fluctuations (Moustafa et al. 2014). In tomato, a purified heat-induced MAPK phosphorylated a heat shock transcription factor, HsFA3 (Link et al. 2002). High-temperature exposure of potato (Solanum tuberosum) tubers leads to marked expression of StMPK1, which helps in stress resistance (Blanco et al. 2006). Further, upregulation of Raf-like MAPKKK, a drought-hypersensitive mutant (DSM1) in rice, provided tolerance to oxidation and dehydration under water deficit in very young seedlings (Ning et al. 2010). Extensive research is underway to increase the adaptability and quality of plants under water and heat stress; for example, Zhang et al. (2011) characterized a cotton MAP kinase (GhMPK2) that limits water losses and regulates homeostasis under drought and heat stress conditions. Similarly a novel MAP kinase (GhMPK16) in cotton related to group D MAPK was identified by Shi et al. (2010). Subcellular quantification confirmed that both GhMPK16 and GhMPK2 are primary regulators of transcription factors and were activated during drought conditions. Danquah et al. (2014) showed that mutant Arabidopsis plants lacking the MKK3 module were less able to control water loss when subjected to a continuous, moderate drought environment. In a similar study, overexpressed cotton GhMKK3 in tobacco exhibited higher resistance to water stress and had more effective stomatal closure in response to abscisic acid (ABA) (Wang et al. 2016a).

The above findings related to MAPK pathways have unveiled an association of the kinases in the signaling events, the identification of pathway targets, and the intricacy of the cascade (Sinha et al. 2011). However, careful manipulation of MAPKs may have constructive effects like in planta high resilience to drought and heat stress. Detailed information regarding the regulation of MAPK cascades, by studying omics (proteomics, metabolomics, transcriptomics) perspectives and in silico database analysis, might aid in the development of innovative techniques to promote heat and drought tolerance in plants (Sinha and Ara 2014).

\section{Calcium-dependent protein kinases}

In plants, calcium-dependent protein kinases (CDPKs) constitute a unique and structurally conserved group of $\mathrm{Ca}^{2+}$ sensors and represent a model for sensing alterations in cytoplasmic $\mathrm{Ca}^{2+}$ concentration (Schulz et al. 2013). CDPKs can effectively sense and transduce signals to specific downstream effectors, and their role has been probed during diverse stress conditions (Liese and Romeis 2013; Fig. 2). Recognition of CDPK targets, along with their corresponding phosphorylation loci, helps in the analysis of CDPK function at both the cellular and genetic level (Boudsocq and Sheen 2013). The complexity of kinaserestricted phosphorylation events within an effector protein indicates that CDPKs serve as signaling cores in controlling plant stress responses and developmental activities (Schulz et al. 2013). CDPKs have long been affirmed to engage in $\mathrm{Ca}^{2+}$-mediated signaling events initiated by various environmental stimuli in relation to water stress and temperature and usually involve ABA-mediated signaling cascades (Asano et al. 2012). CDPK-reliant metabolic fluctuations, alterations in ion fluxes or gene expression have been identified during abiotic stresses, and the triggered expression of the relevant kinase helps in plant stress tolerance (Boudsocq and Sheen 2013). ABA-mediated stomatal closure is a unique phenomenon to reduce water loss during drought conditions, as a first line defense (Munemasa et al. 2015), and various CDPKs have shown to be implicated in the regulation of stomatal activities (Zhang et al. 2014). The enhanced regulatory effect of CDPKs in response to water deficit has been demonstrated by the upregulation of ABA-induced genes (Simeunovic et al. 2016). Notable interactions have been observed between 
AtCPK30, AtCPK10, AtCPK7, AtCPK4, and ABF2 (Lu et al. 2013), and also between AtCPK11 and ABF1 (Lynch et al. 2012). Other members of the kinases, including SnRK gene families, can communicate and phosphorylate ABF2 in ABA-mediated signaling events, as in stomatal closing (Umezawa et al. 2013). Apart from this, CDPK phosphorylation targets have been observed among anion and cation channels; for instance, CPK3 acts as a phosphorylating agent of a two-pore $\mathrm{K}^{+}$channel (TPK1) (Latz et al. 2013). The role of $O s C P K 9$, a rice CDPK gene, was identified in the regulation of stomatal activities and maintaining homeostasis during water deficit (Wei et al. 2014). Their study also showed that OsCPK9 also increases pollen survival, thereby improving spikelet fertility in rice. Similarly, the transcript levels of another rice protein kinase, OsCPK4, were highly upregulated by drought and high salinity, and the transgenic lines overexpressing OsCPK4 gene had higher water-holding capacity and less membrane damage than wild-type (Campo et al. 2014).

In Arabidopsis, CPK8 plays a pivotal role in $\mathrm{Ca}^{2+}$ and ABA-regulated stomatal closure in response to drought stress (Zou et al. 2014). A similar study in grapevine indicated that the VaCPK29 gene might serve a useful regulator of increased heat and osmolarity in callus cell lineages of Vitis amurensis and transgenic Arabidopsis (Dubrovina et al. 2016). Highly effective transcriptional responses were observed in soybean, where, after drought and ABA treatments, about half of all GmCDPKs were highly upregulated, indicating their essential role in abiotic stress resilience (Hettenhausen et al. 2016). A recent study showed that the OsCPK10 isoform confers endurance to multiple stress factors in rice by increasing their antioxidant activity and scavenging free radicals (Bundó and Coca 2017).

These findings indicate that plants need specific sensory mechanisms to withstand changing environmental conditions via a series of interrelated signaling events (Asano et al. 2012). Over the last few years, valuable information has been gathered on plant stress tolerance mechanisms including calcium signaling. Calcium signals control a wide range of processes in plants, and these events are highly regulated (Yu et al. 2014). Comprehensive research in the field of 'omics' has provided beneficial results regarding calcium signaling, but, so far, little information is available on the transduction of $\mathrm{Ca}^{2+}$ signals into high-throughput physiological responses (Simeunovic et al. 2016).

\section{Transcription factors}

Roughly $7 \%$ of coding sequences in the plant genome are exclusively attributed to transcription factors, which act as early abiotic stress-responsive agents. Some TFs respond to stress by linking with the cis-binding domain in the promoter zone of the desired genes decoding metabolic proteins that perform specific functions (Guo et al. 2016). They act as dominant transcriptional regulators for signaling cascades involved in environmental stress tolerance (Lata et al. 2011). Different families of plant TFs (Fig. 2) perform conspicuous functions in deciphering abiotic stress reactivity, mainly by altering gene behavior, and act as key nodes in different signaling episodes (Guo et al. 2016). Major TF families that participate in abiotic stress responses include bZIP, NAC, WRKY, MYB, APETALA 2/ethylene-responsive element binding factor (AP2/ERF) and zinc fingers (ZFs) (Lindemose et al. 2013; Fig. 2). The roles of these TFs in the regulatory network of different environmental stresses including drought and temperature extremes are detailed below.

\section{Basic leucine zipper (bZIP)}

In plants, the basic leucine zipper (bZIP) family represents one of the most diverse TF families, which is involved in several biological functions including seed germination, reproductive development, embryogenesis, and signaling pathways (Sornaraj et al. 2016) and is widely present in various crops. They are also crucial agents in multitudinal abiotic stress tolerance inclusive of drought, temperature extremes, and high osmolarity (Wang et al. 2016b; Fig. 2). The ABA-mediated activation of bZIP TFs and their binding to cis- elements in the promoter region of desired genes enhances the expression of various ensuing stress-responsive genes to enhance stress resilience in plants. The bZIP transcription factor consists of a conserved bZIP domain enfolding two chief components: a highly basic nuclear region and a leucine zipper, cemented together by a hinge region (Hu et al. 2016c). The basic terrain present at the $\mathrm{N}$-terminus is highly enriched with a stabile motif ( $\mathrm{N}-\mathrm{x} 7-\mathrm{R} / \mathrm{K}-\mathrm{x} 9)$ containing 18 amino acid residues accountable for DNA-binding activity and nuclear re-localization (Noman et al. 2017). The subsequent leucine zipper domain consists of leucine-rich motifs at the C-terminus or auxiliary hydrophobic amino acid residues engaged in dimerization and identification of bZIPs (Llorca et al. 2014). In maize, ZmbZIP17 (an ER stress regulator) communicates with $\mathrm{ABA}$-responsive cis-binding elements (ABRE) in the promoter region (Yang et al. 2013). Various abiotic stress-induced transcription factors in bread wheat including bZIP and $\mathrm{C}_{2} \mathrm{H}_{2}$ are thought to intensify stress endurance and climatic resilience $(\mathrm{Xu}$ et al. 2014a). Studies involving transgenics have validated their involvement in imparting stress tolerance. For instance, in cotton, overexpression of maize $A B P 9 \mathrm{bZIP}$ 
transcription factor increased resilience to drought associated with ABA-linked signaling cascades (Wang et al. 2017a; Table 1). Overexpression of the OsbZIP23 gene in rice plants enhanced ABA-linked responses during and after germination which were exclusively linked to heightened stress resilience (Xiang et al. 2008). Upregulation of a bZIP TF, TaABL1, in wheat imparts multitudinal stress resilience including drought and heat which is an important genetic resource for developing transgenic plants (Xu et al. 2014a). Another peculiar nuclear localized $O S H B P 1$ (Oryza sativa, histone gene-binding protein) has been isolated from rice, and overexpresssors showed better survival rate under drought conditions (Lakra et al. 2015). OsHBP1b belongs to bZIP family of transcription factors that activates ROS detoxification system and increases the content of protective molecules (i.e., soluble sugars and proline) under stressed conditions. A putative $\mathrm{H}_{2} \mathrm{O}_{2}$ and ABA-responsive $\mathrm{C}_{2} \mathrm{H}_{2}$-type zinc finger protein OsMSR 15 (Oryza sativa multi-stress-responsive protein) has been also identified in rice that enhances drought and oxidative stress tolerance via elevating antioxidant activities and ABA sensitivity (Zhang et al. 2016). The biological role of another plant-specific protein-GRAS protein family (Gibberellic Acid Insensitive GAI, Repressor of GAI, and SCARECROW, acting as bZIP transcription factors) in conferring abiotic stress tolerance in rice has been also explicated recently; enhanced expression of OsGRAS23 in transgenic rice resulted in high drought as well oxidative stress resilience via reducing $\mathrm{H}_{2} \mathrm{O}_{2}$ accumulation ( $\mathrm{Xu}$ et al. 2015). Similarly, another novel bZIP transcription factor, i.e., OsbZIP46 (Oryza sativa), is highly induced by drought, heat, and $\mathrm{ABA}$-applications, and the upregulation of OsbZIP46 enhances resistance to drought as well as ABA in transgenic rice (Tang et al. 2012).

Overexpression, regulation, or silencing of protein clusters associated with TFs is the most accepted gene manipulation regimen pursued for reinforcing stress resilience in plants (Sornaraj et al. 2016). These TFs do not function alone, but work synergistically with other TFs, chromatin proteins, and cofactors to sustain abiotic stress tolerance (Baloglu et al. 2014). Some studies indicate that alteration of bZIP TFs and associated proteins appears to be necessary for novel genetic engineering strategies (Wang et al. 2017a).

\section{NAC transcription factors}

Among all lineages of TFs in plants, NAM, ATAF, and CUC (NAC) are the largest group of transcription factors modulating plant growth and metabolism and abiotic stress responses (Pandey et al. 2016; Fig. 2). The epithet NAC is alienated from the first character of three genes that was originally identified to represent a NAC domain: NAM,
ATAF1:2, and CUC2 (cup-shaped cotyledon) (Tran et al. 2010). Recently, various stress-responsive NAC TFs were used to engineer stress-tolerant varieties of crop plants using transcriptional reprogramming (Sakuraba et al. 2015). These stress-responsive TFs not only behave as molecular markers in gene expression but as the terminating notch in signal transducing pathways, regulating their differential expression (Puranik et al. 2012). Remarkably, a significant number of NAC TFs have been reported from diverse plants species, but not much is known about their functional aspects under stress environments (Hu et al. 2010). NAC transcription factors were first reported in Petunia species as NAM (No apical meristem) which is essential in the development of shoot meristem (Guo and Gan 2006). Later, they were well characterized in A. thaliana and $O$. sativa (Rushton et al. 2008). Comprehensive analysis of several functional genomics sequences in plants led to the identification of 110 NAC genes in Arabidopsis, 151 in rice, 152 each in soybean and tobacco, 79 in grape, and 26 in citrus (Le et al. 2011). Entire genome sequence profiling in Arabidopsis revealed their expression in different stress signals including heat, drought, or osmotic stress (Lindemose et al. 2013). The molecular tailoring of NAC TFs may assist in breeding transgenic crop plants for improved growth and yield under stress (Puranik et al. 2012). NAC proteins are suggested to regulate the abiotic stress-induced defense mechanisms including multigene expression in plants probably through ABA-dependent or ABA-independent signaling cascades (Shao et al. 2015). Nonetheless, all discovered NAC TFs are involved in stress responses, and particularly, the subfamily IV of NAC TFs is broadly found to be engaged in sustaining homeostasis under drought and heat stress (Hao et al. 2011). Various studies have reported that expression of the ANACO19 gene is stimulated by many stresses, especially drought stress, and the application of ABA. As ABA performs a pivotal function in seedling germination as well as salt and drought stress sensitivity, there might be a significant relation between ABA and ANAC019 during stress (Jensen et al. 2010).

In Arabidopsis, drought tolerance is administered by three NAC genes, AtNAC072, AtNAC055, and AtNAC019, through their interaction with the ERDI promoter region (Mao et al. 2014). Likewise, transgenic Arabidopsis plants overexpressing RhNAC2 (Rosa hybrida) from rose petals showed high drought tolerance (Dai et al. 2012; Joshi et al. 2018). Further, in barley, ATAF1 and ATF2 TFs, together with the HvNAC6 gene, act as important participants in regulating seed germination and drought stress responses (Yamaguchi-Shinozaki and Shinozaki 2006; Pérez-Clemente et al. 2013). In rice roots, upregulation of OSSADRI (salt, ABA, and drought stress-induced RING finger protein, in the presence of ABA increases tolerance to drought stress via interacting with some nuclear localized $O S N A C 2$ proteins (Park et al. 2018). Evidences signified that overexpression of a few 
NAC genes (i.e., OsNAC1, OsNAC5, OsNAC6, OsNAC045, OsNAC052, and OsNACO63) in rice plants also intensified stress endurance during drought and heat stress (Chew and Halliday 2011). SNAC1 was identified to be a master regulator for enhancing drought resistance of transgenic rice in the field (Hu et al. 2006), and OSPP18 is one target of SNAC1 (You et al. (2014). Likewise, transgenic rice plants overexpressing SNAC3 (ONAC003, LOC_Os01g09550) showed improved tolerance to drought as well as heat stress due to less accumulation of reactive oxygen species (Fang et al. 2015). Recently, Mao et al. (2015) identified a ZmNAC111 in maize that improved water-use efficiency under drought stress via upregulating various drought responsive genes. Similarly, overexpression of ZmNAC55 in transgenic maize plants induces drought stress tolerance and hence may act as potential candidate for breeding drought tolerant lines via transgenic techniques (Mao et al. 2016). A large variety of NAC TFs were also identified and sequestered in wheat with distinct expressions induced by diverse abiotic stresses. TaNAC2, TaNAC2a, and TaNAC69 are some examples of possible TFs for ameliorating abiotic stresses via generation of transgenic plants (Hong et al. 2016). Considering their suggested role in stress response, the manipulation of these multiple stress-linked TFs, especially multifunctional NAC TFs, may contribute to breeding stress-tolerant crops plants with high yield potential.

\section{WRKY transcription factors}

The plant-restricted WRKY transcription factors are one of the largest families of transcriptional regulons with multiple biological roles in plant abiotic stress signaling, embryogenesis, and seed maturation that supplement other developmental and hormone-regulated processes (Tripathi et al. 2014). WRKY TFs carry the redundant amino acid sequence WRKYGQK (W-box) at the DNA-binding core and the zinc finger-like motif Cys2-His2 attached to the cisdomain in the promoter terrain of the desired genes (Bakshi and Oelmüller 2014). An analytical study of signaling events and transcriptional reprogramming identified an interaction between WRKY proteins and calmodulins, MAPKs, histone deacetylases, and other WRKY transcripts (Banerjee and Roychoudhury 2015; Fig. 2). WRKY TFs are also essential factors in the plant signaling lattice, which not only monitors plant responses to multitudinal abiotic stimuli, but functions in synchronization with intrinsic signals related to developmental processes by interacting with additional DNA-linked and non-linked proteins (Jiang et al. 2017). WRKYs TFs have been identified and isolated in all higher plants and in some lower flora and are integrated into discrete plant processes, along with growth, reproduction, and stress signaling (Phukan et al. 2016). Genome-wide sequencing and the analysis of TFs from other plants identified more WRKY genes in plants such as soybean, rice, mustard, and Arabidopsis (Fan et al. 2015; He et al. 2016).

Considerable attention is being paid to the functional roles of WRKY genes in plants exposed to drought, heat, and osmotic stress (Chen et al. 2017). Numerous WRKY TFs have been identified in plants in response to heat stress (Li et al. 2011). In Arabidopsis, overexpression of AtWRKY25 and AtWRKY26 provides tolerance to elevated temperatures ( $\mathrm{Li}$ et al. 2011). Likewise, the TaWRKY44 transcript in wheat acts as a positive regulon for drought and osmotic stress either as a potent ROS scavenger via initiation of the antioxidant defense activities or by upregulating various stress-responsive genes (Wang et al. 2015). Moreover, TaWRKY33 transgenics had reduced susceptibility to heat stress (He et al. 2016). Similarly, the GhWRKY4l gene in transgenic tobacco imparts drought and heat tolerance by reducing ROS production and stomatal conductance (Chu et al. 2015). In Brassica napus, transcripts of three WRKY TFs, BnaWRKY210, BnaWRKY166, and BnaW$R K Y 147$, were strongly upregulated under drought stress, signifying their participation in stress tolerance (Jiang et al. 2017). Similarly, GhWRKY68 transcripts in cotton influenced drought stress response by altering the expression of ABA-responsive genes and ROS detoxification (Jia et al. 2015). The participation and interaction of these multiple presiding WRKY TFs with other stress-related genes need to be explored (Shanker et al. 2014). Further examination of their function in molecular and mutant studies will shed light on their potential to sustain plants under a combination of stress responses (Zhang 2014). In addition, the mode of coordinated responses to multiple stresses related to WRKY TFs as well as their targets would be highly exciting (Wang et al. 2016b).

\section{MYB transcription factors}

The MYB TF family represents a large and functionally dissimilar class among eukaryotic organisms, which is delineated by the presence of an invariant MYB domain at the $\mathrm{N}$-terminus and a modulating network of proteins at the C-terminus (Roy 2016). In higher plants, the MYB superfamily is a highly specialized and broad group of R2R3MYBs containing various MYB repeats in their sequences unveiling DNA-binding activity (Baldoni et al. 2015). The R2R3-MYB proteins have a fundamental role in regulating numerous plant functions, including growth, metabolism, and ABA-mediated reactivity to biotic or abiotic stimuli (Kharte et al. 2016). The recent advancements in genetic and molecular approaches have promoted the large-scale characterization of functional MYB proteins, especially R2R3-type classes in crop plants including soybean, rice, and maize (Roy 2016). Analysis of the Arabidopsis genome revealed the presence of 168 MYB TFs, denoted by a sequence repeat 
of R2R3-MYB domain, five R1R2R3-MYB, 64 MYB like and three anomalous MYB genes (Zhang et al. 2010). Various members of the R2R3-like MYB TFs are intricated in their governance of phenyl-propanoid pathway synthesizing various secondary metabolites in response to abiotic stress in plants (Roy 2016). In Arabidopsis, expression of several MYB transcription factors, including AtMYB102, AtMYB74, and $A t M Y B 2$, was induced during drought conditions (Baldoni et al. 2015). Previous data have indicated the involvement of MYB TFs in ABA-mediated drought stress signaling (Xie et al. 2014). For instance, the Arabidopsis MYB96 gene is involved in lateral root initiation during drought through the interaction of auxin and ABA signaling events (Zhang et al. 2010). A MYB-type TF from sugarcane (ScMYB76) was identified under drought stress conditions (Balakrishnan et al. 2016). Further, overexpression of buckwheat FtMYB9 in transgenic Arabidopsis enhanced tolerance to water-deficit conditions (Gao et al. 2016; Table 1). In another example, Chen et al. (2015a, b) showed that GbMYB5-a MYB transcription factor in cotton (Gossypium barbadense) improved drought tolerance by increasing the accumulation of compatible solutes. The above findings indicate that MYBs genes could be used as efficient candidates for enhancing growth under stress conditions (Baldoni et al. 2015). The main constraint in this regard is that functional genomics studies have been restricted to laboratory conditions, as experimentation in open field is challenging (Roy 2016).

\section{AP2/ERBP transcription factors}

During episodes of proliferation of the eukaryotic genome and DNA-binding proteins, new families of TFs evolved (Licausi et al. 2013). Of these, the novel APETALA2/ethylene-responsive factor (AP2/ERF) superfamily exemplifies a benchmark to these episodes ( $\mathrm{Gu}$ et al. 2017). Although, the AP2/ERF domain was initially identified in plants, it has been found in the genome of some cyanobacteria and protists (Du et al. 2014). In plants, the AP2/ERF superfamily, comprising 119-200 members, has been widely explored in relation to senescence, fruit ripening, ethylene, and abiotic stress responses (Shu et al. 2016). AP2/ERF proteins are highly proficient in binding to a wide array of cis-elements in the promoter region of desired genes (Zong et al. 2016). DREB/ CRT (dehydration response element binding proteins/Crepeat, RCCGCC element) and ERF/GCC-box (ethyleneresponsive factor, AGCCGCC element) represent two main DNA-binding cis-regulatory elements of AP2/ERF (Wang et al. 2016b). Most DREB proteins respond to drought and ABA signaling, whereas, members of the ERF family are specifically linked to ethylene-mediated responses or pathogenesis (Licausi et al. 2013). The activation of DREB1/ CBF-type transcription factors is triggered by two major abiotic stresses, i.e., heat, and drought stress. However, the expression behavior of orthologous genes varies in different species (Yang et al. 2017). In rice, expression of OsDRAP1 (DREB-like genes) was induced by diverse abiotic stresses, and $O S D R A P 1$ overexpressors showed high drought tolerance (Huang et al. 2018). Further, enhanced expression of $Z m D B F 3$ in Arabidopsis and yeast improves tolerance to drought and heat, indicating that $Z m D B F 3$ is a positive mediator of multiple stress tolerance (Zhou et al. 2016). In future, $Z m D B F 3$ might be a candidate gene for improving stress tolerance through genetic modification of the plant genome. Similarly, overexpression of the $\operatorname{VrDREB} 2 A$ gene isolated from mung bean in transgenic tobacco plants conferred higher tolerance to drought stress (Chen et al. 2016). As a whole, the above considerations demonstrate that DREB TFs could be an effective biotechnological tool for improving stress tolerance in important agriculturally significant crops (Yang et al. 2017; Table 1).

\section{Chaperones}

\section{LEA proteins}

Late embryogenesis abundant (LEA) proteins were initially discovered in cotton seeds during the late phases of embryo development as well as being involved in certain developmental activities of plants such as root and shoot development and pollen grain formation (Amara et al. 2014). In addition to seed maturation, some LEA proteins are augmented in the differentiation of meristematic and vascular tissues (Battaglia et al. 2008). LEA proteins have highly intrinsically disarranged structures, commonly referred as "molecular shields" owing to their multifaceted roles in environmental stress resilience (Gao and Lan 2016; Fig. 2). LEA proteins are a broadly distributed category of polypeptides in the plant kingdom, ranging from algae to angiosperms, and have been reported in some fungi and microorganisms such as bacteria (Pedrosa et al. 2015). In higher genera, these structurally related proteins facilitate a wide range of adaptation to water-deficit environment in somatic tissues (Shih et al. 2008). Despite abundant diversity and variability, LEA proteins were initially classified into six groups according to their amino acid sequences and ubiquity of specific domains (Battaglia and Covarrubias 2013), most of which belong to the hydrophillins, a broadly dispersed group of unstructured proteins distinguished by the presence of charged amino acid residues. Hydrophillins were first characterized in cotton embryos based on the presence of conserved specific motifs and homology of amino acid sequences (Dure et al. 1981). The association of LEA proteins during water stress assists in the widespread adaptation of plants to water stress; however, their specific functions are still ambiguous (Amara et al. 2014). 
During water stress, the activity of LEA proteins is upregulated to prevent target proteins from denaturation and aggregation (Manfre et al. 2006). Their functional role in protein stabilization is documented by the fact that in vitro enzyme activity is sustained by LEA proteins even after desiccation (Reyes et al. 2005). Membrane protection is crucial for conserving cellular as well as organellar rationality during desiccation (Tunnacliffe et al. 2010). Another consequence of dehydration stress is the enhanced concentration of intracellular content, especially ions, which can disrupt macromolecular function and conformation (Kovacs et al. $2008 \mathrm{a}, \mathrm{b})$. As LEA proteins contain many charged amino acid residues, they might be involved in ion sequestration during desiccation. Group 2 LEA proteins (dehydrins) from celery were reported in the vacuole which binds to $\mathrm{Ca}^{2+}$ when phosphorylated through histidine residue (Alsheikh et al. 2005). LEA proteins can also bind to some metal ions $\left(\mathrm{Fe}^{+3}, \mathrm{Ni}^{+2}, \mathrm{Cu}^{+2}\right.$, and $\left.\mathrm{Zn}^{+2}\right)$ attributable to their antioxidant activity, for instance, the CuCOR19 protein in citrus displays scavenging activity for hydroxyl radicals, thus reducing oxidative stress (Hundertmark and Hincha 2008). In some cases, LEA proteins may act as hydrating buffers and slow down the rate of water loss during drought, osmotic or freezing stress to retain the function of desiccating cells (Banerjee and Roychoudhury 2016).

In plants, previous evidences indicate that overexpression of LEA proteins imparts tolerance to varied water-deficit conditions (Eriksson and Harryson 2011; Duan and Cai 2012). To some extent, it has been delineated that the inadequacy of either one or two LEA4 proteins in A. thaliana is sufficient to enhance water stress sensitivity (Ismail et al. 1999). In some legumes (Phaseolus vulgaris, Medicago truncatula, Lotus japonicas, Cajanus cajan, and Cicer arietinum), different LEA proteins with distinct motifs have been analyzed by sequence database analysis (Varshney et al. 2012, 2013).

Considering the above facts, it is clear that a single LEA protein can perform multiple functions; for example, the chloroplastic LEA protein (COR15am) and the mitochondrial Group 3 proteins (LEAM) are engaged in protecting both membranes and proteins. In rice, a LEA protein, (HVA1) stimulated root induction and multiple stress resilience through ABA/stress inducible promoter (Chen et al. 2015b). Similarly, Group 3 LEA proteins located in the vacuole of citrus assisted in ion sequestration and exhibited antioxidant as well as nucleic acid binding ability (Pedrosa et al. 2015). Overexpression of a novel LEA protein, SiLEA14, in Arabidopsis and foxtail millet imparted high tolerance to drought and high osmolarity (Wang et al. 2014b). Likewise, upregulation of the OsEml gene enhanced resilience to different stresses including drought and $\mathrm{ABA}$ in rice $(\mathrm{Yu}$ et al. 2016). Transgenic plants had enhanced stress tolerance relative to wild-type plants, usually during drought stress
(Banerjee and Roychoudhury 2016). LEA proteins could be beneficial for other biotechnological applications due to their ability to prevent the disintegration of proteins (Kosová et al. 2014). While relevant analysis has been conducted to interpret the role of LEA proteins, the molecular means for improving stress adaptability remains ambiguous (Liu et al. 2013). Further perspectives including transcript or gene expression patterns should be explored to determine the involvement of other LEA-dependent regulatory mechanisms for investigating abiotic stress responses in plants.

\section{Dehydrins}

Dehydrins represent a highly hydrophilic group of plant proteins, which belong to a sizeable biochemical family of LEA proteins and were initially characterized in cotton seeds (Allagulova et al. 2003). They are well recognized as LEA D-11 or LEA II proteins and play an important role in plant abiotic stress responses (Ingram and Bartels 1996). Among all abiotic stress-related TFs, dehydrin's expression is more pronounced during drought, heat, and desiccation stress and is also induced by enhanced ABA contents (Wahid and Close 2007). Originally designated "dehydration-induced proteins" on the basis of their mechanism of expression (Graether and Boddington 2014), they were later specified according to their unique sequential motifs and presence of lysine-rich conserved amino acid sequence, i.e., a K-fragment usually present near the C-terminus (Malik et al. 2017). Dehydrin molecules also contain partially conserved sequential motifs abundant in hydrophilic a $\Phi$-segments and glycine (Hughes et al. 2013).

The first dehydrin protein was isolated in rice as RAB21 or RAB16A (Mundy and Chua 1988). A diverse range of dehydrin proteins has been isolated in angiosperms such as rice and cotton, as well as some species of mosses, ferns, lycopods, and gymnosperms (Liu et al. 2016). In angiosperms, especially dicotyledons, dehydrins have been characterized in small herbaceous plants such as $A$. thaliana as well as large, long-living woody species such as silver birch (Betula pendula) (Puhakainen et al. 2004), beech (Fagus sylvatica) (Jiménez et al. 2008), poplar (Populustremula) (Renaut et al. 2005). It has been observed that the upregulation of the dehydrin gene, OsDhn1, improved drought tolerance in rice through the detoxification of ROS (Lee et al. 2005). Similar role of $O s D h n l$ in mediating drought resistance has been speculated by Kumar et al. (2014). The exaggerated expression of Solanum habrochaites dehydrin gene $(S h D H N)$ in cultivated tomato conferred tolerance to drought and temperature stresses (Liu et al. 2015). The SiDHN gene from snow lotus (Saussurea involucrate) provided tolerance to drought stress (Guo et al. 2017), suggesting that SiDHN could be a potential candidate for genetically enhancing plant resistance to water deficits. Recently, five dehydrin 
genes from Prunusmume (PmLEAs) were characterized using RT-PCR, and transmutant tobacco overexpressing these genes had improved acclimation to drought stress (Bao et al. 2017).

Similar to LEA proteins, dehydrins accumulate abundantly in plant embryos in late developmental stages (embryo maturation and desiccation) (Malik et al. 2017). In vegetative tissues, their existence is confined to young meristematic tissues, i.e., root tips, shoot apex, and petioles. However, when plants experience multiple abiotic stresses related to cellular water deficit (heat, drought, and osmotic stress), dehydrins accumulate in all vegetative tissues (Eriksson et al. 2016). There is evidence that a specific interrelationship exists between dehydrin gene expression and plant abiotic stress tolerance (Graether and Boddington 2014). Hence, dehydrins may serve as an important plant molecular marker in plant abiotic stress responses (Hanin et al. 2011).

\section{Osmotins}

Osmotins are versatile and multifaceted stress-responsive PR-5 proteins that confer stress tolerance in plants to biotic and abiotic factors (Anil Kumar et al. 2015). In reference to their isoelectric point (pI), PR-5 proteins are further categorized into three functional groups: neutral (osmotin-like proteins-OLPs), acidic (PR-S), and basic (osmotin) (Van Loon and Van Strien 1999). Osmotins were originally analyzed in tobacco plants suffering from tobacco mosaic virus, and elevated levels were also observed in young leaves facing salt stress (Singh et al. 1989). Osmotins are activated during osmotic stress in plants to decrease water potential (Aliprantis et al. 1999; Hong et al. 2004; Fig. 2). Osmotic adjustment is a key phenomenon for maintaining water balance and cell turgor during osmotic stress and thus contributes to enhanced photosynthetic efficiency and growth (Das and Chakraborty 2016). Osmotins impart osmo-tolerance to plants possibly through ion sequestration or conferring protection through some structural or metabolic alterations at the cellular and molecular level (Viktorova et al. 2012). Along with OLPs (Osmotin-like proteins), they negotiate abiotic stress responses in plants and their increased expression is mostly determined by drought (Atkinson and Urwin 2012), desiccation, or chilling/freezing stress (Aslam et al. 2009). During oxidative stress, OLPs are expressed in the quiescent center of root apices and meristematic zone of shoot apex (Bobbert et al. 2005). Transgenic as well as wild expression behavior of osmotin and OLPs has been confirmed in a wide variety of plants facing multiple biotic and abiotic stresses. However, the signaling mechanisms related to their upregulation during different stresses are still unknown (Anil Kumar et al. 2015). The physiological role of
RSOSPRIO (rice root-specific pathogenesis-related protein) under different abiotic stresses has been reported recently (Takeuchi et al. 2016). Their data showed that RSOsPR10 overexpression in transgenic rice provided high drought resistance. Transgenic bent grass overexpressing $R S O S P R 10$ also showed better resistance to drought, thus validating its function. Overexpression of osmotin in transgenic plants increased leaf area, chlorophyll, and relative leaf water content in response to drought stress (Husaini and Abdin 2008). These findings suggest that osmotin is capable of protecting chlorophyll molecules and photosynthetic apparatus under water deficit. Transgenic expression of osmotin in mulberry plants with the $r d 29 \mathrm{~A}$ promoter also induced high drought tolerance (Das et al. 2011). Osmotin and its corresponding promoters are transcriptionally regulated by ABA in plants (Nelson et al. 1992). Osmotins also regulate the production of ROS and activate antioxidant defense machinery under different environmental conditions (Xiong and Zhu 2002). Thus, transgenic plants overexpressing osmotins neutralize ROS by stimulating the production of more compatible osmolytes or expression of corresponding antioxidative enzymes (Khan et al. 2015). The above findings indicate that osmotins are beneficial for optimizing the yield and productivity of diverse crop species to water-limited environments. Engineering these proteins might unravel various complexities associated with abiotic stresses in crop plants.

\section{Heat shock factors and heat shock proteins}

The heat shock transcription factor (HSF) family is the most widely studied TF family in plants (Udvardi et al. 2007). Various studies have been undertaken to determine the multifaceted roles of HSFs in abiotic stress tolerance including heat stress; it is now clear that HSFs function predominantly in individual stress responses, rather than a combination of stresses (Sewelam et al. 2014). HSFs in plants are wellaccomplished modular structures characterized by the N-terminus DNA-binding motif (DBD) that interact with heat stress cis-elements (HSEs) in the destined regions (Lata and Prasad 2011). HSFs act as a terminal notch in signal transduction pathways and subsequently mediate the transcriptional upregulation of diverse stress-responsive genes (Baniwal et al. 2004). On one side of the DBD, a peculiar oligomerization domain (OD) with hydrophobic amino acid residues (HR-A/B region) remains attached by a flexible linker (Baniwal et al. 2004). Plant HSFs are categorized into three classes, HSF A, HSF B, and HSF C, on the basis of the distance between the DBD and HR-A/B regions linked by a flexible linker (Kotak et al. 2004). The C-terminus domains are highly activated, distinguished by precise peptide motifs (AHA motifs), which are essential modulators of protein functions (Kotak et al. 2004). 


\section{Heat shock proteins}

Heat shock proteins, (HSPs) proteins act as molecular chaperones attributable to their role in perpetuating cellular stability in cells subsidiary to optimal as well harsh growth conditions (Wang et al. 2014a). HSPs assist in protein folding during cellular metabolism (Wang et al. 2004), stabilize membrane proteins, and facilitate protein refolding during exposure to stress (Wahid et al. 2007). Moreover, an inclusive category of HSPs exhibits chaperone activity during three-dimensional protein folding and destruction caused by stress (Kotak et al. 2007).

Heat shock proteins are categorized into five highly conserved subfamilies on the basis of their molecular weights as Hsp60, Hsp70 (DnaK), Hsp90, Hsp100 (Clp), the chaperonins (GroEL), and the small HSP (sHsp) family (Kotak et al. 2007). The course of action of HSPs is peculiar; they specifically bind to target substrates without forming covalent bonds (Wahid et al. 2007). Except for the sHsp family, limited attention has been given to the functionality of most of the HSPs/chaperones in plant abiotic stress responses (Kregel 2002). Hsp60, Hsp70, and Hsp90 behave as molecular shields during stress conditions by communicating with an inclusive array of co-chaperone proteins that assist in the assemblage of peculiar substrate proteins by regulating their activity (Liberek et al. 2008). Genome analysis revealed the existence of approximately 13 sHsps, seven Hsp60, 18 Hsp70, seven Hsp90, and eight Hsp100 members in A. thaliana (Zhang et al. 2015). Plant species such as maize and wheat also express HSPs during episodes of abiotic stresses (Kumar et al. 2012). By altering the genetic constitution of HSPs, new stress-tolerant varieties can be engineered; for instance, overexpression of Hsp101 in Arabidopsis and rice provided tolerance to extreme temperatures (KatiyarAgarwal et al. 2003). The upregulation of Hsp70 imparts tolerance to drought, and heat as reported in transgenic tobacco, where overexpression of NtHSP70 enhanced tolerance to heat as well as drought in transgenic tobacco lines (Udvardi et al. 2007). The sHsps are a diverse and abundant category of proteins that may emulate their response to counterfeit transient changes in external environmental (Sun et al. 2012). These sHsps proteins accumulate not only during sublethal temperatures, but in response to osmotic stress. Considering the above facts, triggered synthesis of HaHsp17.6 (class CI) and HaHsp17.9 (class CII) genes has been reported in the stem and roots of water-deficit sunflowers (Tuteja and Gill 2016). Similarly, the significance of chloroplast sHsps was revealed in Agrostis stolonifera grass, where sHsp26.2 was related to heat tolerance in susceptible variants (Zhu et al. 2012). OsHSP18.2 (Oryza sativa) in rice acts as molecular chaperone and improves seed quality and viability under adverse stimuli by inhibiting ROS synthesis (Kaur et al. 2015). Several heat shock proteins were also upregulated in rice cultivars overexpressing golgi/plastid OsMSD1 (Oryza sativa manganese superoxide dismutase 1) that improved grain quality under heat stress (Shiraya et al. 2015). OsMSDI has been reported to express actively in the endosperm and embryo of developing seeds in rice (Shiraya et al. 2015).

Individually, each member of HSP/chaperones has peculiar role, but the coordinated function of different HSP/chaperone networks emerges as a key for stress tolerance. However, the role of HSPs/chaperones as regulatory and sensing molecules in signal transduction and transcription pathways during stress remains unclear, and research in relation to the functional aspects of HSPs/chaperones in stress tolerance is in progress.

\section{Stress-associated proteins (SAPs)}

A family of stress-associated proteins (SAPs) has recently attracted attention in several studies on abiotic stress responses in plants (Giri et al. 2013; Dixit and Dhankher 2011; Kanneganti and Gupta 2008). The SAP gene family has emerged as a unique class of ZFPs (zinc finger proteins) that have been evolutionarily conserved among various plant species (Giri et al. 2013; Vij and Tyagi 2008). Approximately, 14 genes encoding SAP proteins in Arabidopsis thaliana and 18 in Oryza sativa genome have been identified (Vij and Tyagi 2006). The presence of SAP-like proteins in the genomes of other organisms including fungi, protists, and animals has been reported (Vij and Tyagi 2008). SAPs are characterized by a distinct A20/AN1 zinc finger terrain with repeated Cys2-Cys2 finger motifs or Cys2-His2 finger motifs (Dixit et al. 2017) and were initially identified in rice (Mukhopadhyay et al. 2004). Most SAP genes are induced by abiotic stressors such as heat and drought in rice (Vij and Tyagi 2006; Dixit and Dhankher 2011). The latest evidence is that the constant expression of SAP gene homologs in cotton, tobacco, Arabidopsis, wheat, and banana increases endurance to multiple abiotic stresses, including drought as well as heat (Dansana et al. 2014). Despite detailed insight into SAPs function in plants, their mode of action in conferring stress tolerance is not clear yet. The compilation of available data on SAPs may be beneficial in evaluating their functional aspects for enhanced yield stability and abiotic stress tolerance in plants (Giri et al. 2013). SAP gene products may be involved in stress signaling through stable protein-protein interactions with zinc finger motifs (Kothari et al. 2016). SAPs may emerge as novel targets for improving stress tolerance, specifically with stress-responsive promoters (Ghneim-Herrera et al. 2017). Functional analysis of the ShSAPl gene from sugarcane indicated that ShSAPl might confer drought and osmotic stress tolerance in transformed tobacco (Li et al. 2014b). However, a TaSAP5 protein from wheat acted as an E3 ubiquitin ligase to degrade the DRIPs, 
which enhanced the expression of DREB2A proteins, and further improved grain yield as well as survival in transgenic Arabidopsis under drought stress.

Enhanced expression of OsiSAP1 and OsiSAP8 from Oryza sativa, each with one AN1/A20 motif, increased tolerance drought stress in transgenic rice as well as tobacco (Dansana et al. 2014; Kanneganti and Gupta 2008; Mukhopadhyay et al. 2004). Likewise, the constitutive expression of ZFP177 (OsSAP9) in rice was induced by heat and oxidative stress, but it remained unaltered with drought stress (Huang et al. 2008). SAP genes were also expressed in Arabidopsis and maize during drought and osmotic stresses in a highly specific manner (Dansana et al. 2014). Upregulation of $A I S A P$, an SAP from Aeluropus littoralis (a halophyte grass) in transgenic durum wheat, rice, and tobacco, improved yield and productivity under stress conditions (Saad et al. 2010; Ben Saad et al. 2012). Similar findings were reported in Arabidopsis, where OsSAP1 from rice protected yields during water stress (Giri et al. 2011). Upregulation of the $A$. littoralis, AlSAP gene in rice, also enhanced grain yield by 50-90\% under drought stress in the field (Ghneim-Herrera et al. 2017). The expression of Prunus persica, PpSAP1, was induced by heat and water stress and increased water retention ability in transgenic plums (Lloret et al. 2017). Similarly, in Arabidopsis, overexpression of AtSAP13 transcripts improved tolerance to drought along with other stresses (Dixit et al. 2017).

As plant SAPs participate in various physiological functions by interacting with various other proteins, they may act as regulators of abiotic stress tolerance in plants (Kothari et al. 2016). However, comprehensive evaluation and understanding of their role in multifaceted signaling/regulatory cascades is required to make use of their potential in yield stability under abiotic stresses.

\section{Physiological relationship between drought and heat stress}

The physiological effects of drought and heat stresses are linked and mutual (Prasad et al. 2008). For instance, decline in stomatal conductance and transpiration under water-deficit conditions may result into heat stress because of rise in leaf temperature (Król 2013; Sehgal et al. 2017a, b). Drought stress leads to reduced root hydraulic conductivity to prevent water loss from the plant. Extreme temperatures can induce stomatal closure and also accelerate root moisture loss resulting in drought stress (Parent et al. 2010). Photosynthetic efficiency and transpiration rates have shown to decrease under drought and heat stress, when applied individually or in combination (Lamaoui et al. 2018; Sehgal et al. 2017a, b; Sita et al. 2017). This is mainly because of stress-induced stomatal closure but can also be as a result of reduced leaf expansion, leaf senescence, and impaired functioning of the photosynthetic machinery (Saibo et al. 2009; Rahnama et al. 2010). The latter situation is often attributed to the decreased internal availability of $\mathrm{CO}_{2}$, in addition to inhibition of key photosynthetic enzymes and ATP synthases (Zlatev and Lidon 2012; Zandalinas et al. 2016). Both heat and drought stresses are reported to impair the electron transport, degrade proteins, release magnesium and calcium ions from their protein-binding partners (Rexroth et al. 2011; Zlatev and Lidon 2012; Zandalinas et al. 2016). Prolonged exposures to exorbitant temperatures as well as drought can result in reduced chlorophyll content, increased amylolytic activity, disintegration of thylakoid grana, and disturbed assimilates' transport (Kozlowska et al. 2007). These stresses induce elevated levels of ROS, depending upon their predominance, which cause damage to proteins, lipids, and DNA ultimately resulting in oxidative stress (Zlatev and Lidon 2012; Awasthi et al. 2015) to upregulate various antioxidants to combat the toxic effects of ROS (Mittler 2002; Gill and Tuteja 2010). The accumulation of osmolytes is also a common response to drought and heat stress, aimed to stabilize and protect proteins, membranes and maintain the water relations (Zandalinas et al. 2018). Moreover, several phytohormones are involved in response to drought and heat stress to control multiple events, which may be common to both the stresses. For instance, abscisic acid (ABA) is a key hormone involved in conferring tolerance to abiotic stresses such as drought and heat (Zhang et al. 2006; Lata and Prasad 2011). ABA has always been considered as a major chemical involved in root-to-shoot stress signal (Suzuki et al. 2013), inducing inhibition of leaf expansion and short-term responses like stomatal closure. $\mathrm{ABA}$ is involved in the regulation of systemic responses to abiotic stress before there are any changes that can be deciphered in leaf water or nutrient status (Bauer et al. 2013; Suzuki et al. 2013). Recently, new retrograde signals such as the metabolite 3'phosphoadenosine 5'-phosphate have been considered to accumulate during high-temperatures and drought conditions, moving from chloroplast to nucleus to regulate $\mathrm{ABA}$ signaling and stomatal closure during the oxidative stress, to induce drought tolerance (Pornsiriwong et al. 2017).

\section{Proteins associated with combined heat and drought stress response}

Since the episodes of drought and heat are predicted to rise in the coming future (Team et al. 2014), there is an immediate need to study the molecular responses of plants to these stresses, especially their combination, for devising strategies 
to improving the yield and productivity of food crops (Barnabás et al. 2008). Both heat and drought stress have several damaging impacts on various traits; crop yield and productivity are negatively influenced by decreased water supply and high temperatures due to morphological and physiological disruptions (Lesk et al. 2016). Various studies have investigated the effects of drought and heat stress, applied individually, or in combination, on plant growth and productivity, suggesting that these stresses causes severe damage, when combined, as compared to individual stress factor (de Boeck et al. 2016; Zandalinas et al. 2016; Awasthi et al. 2017; Sehgal et al. 2017a, b). It is worth mentioning that the sequential imposition of drought and heat stress does not affect general response to combination of stresses (Zandalinas et al. 2017). Though all the plant species, investigated for their responses to individual effects of stresses, showed early similar physiological response to these stresses, the combined action of both stresses was found to be more deleterious and even unique than the individual stress factor. The plants seem to have adopted specific defensive means to counter the combined severity of heat and drought (Fahad et al. 2017). The joint effect of heat and drought stress resulted in early stomatal closure, more reduction in photosynthesis, and substantially increased leaf temperature, as observed in tobacco, compared to their individual treatments (Rizhsky et al. 2004). The responses to these situations were found to be unique. For example, some transcription factors encoding dehydrins, catalases, and glycolate oxidases were activated during drought, and some were activated during heat stress, for instance, thioredoxin peroxidase, while ascorbate peroxidases were down-regulated during combination of both drought and heat shock (Rizhsky et al. 2004). Moreover, other transcription factors, such as WRKY transcripts, glutathione peroxidase, alternative oxidase, phenylalanine ammonia lyase, pathogenesis-related proteins, and an ethylene -responsive element-binding protein, were exclusively expressed during the combined shock of heat and drought stress (Rizhsky et al. 2004). In another instance, in three-day-old seedlings of wheat exposed to heat and/or drought, cyclophilin (wCyp-45) proteins were more induced under combined heat and drought stress as compared to individually applied stress (Sharma and Kaur 2009). A further study on combined effects of heat and drought stress in two wheat cultivars, viz. resistant cv. Katya and susceptible cv. Sadovo (Grigorova et al. 2011) showed that heat shock proteins, HSP70, HSP100 and (smHSPs), were more expressed in both cultivars under the combination of both stresses than individually applied stress. The expression of HSP70, HSP100 and (smHSPs) was increased to eightfold during drought and almost tenfold during combined drought/heat; however, no change in the expression behavior of HSP70, HSP100 and (smHSPs) was observed during heat stress alone (Grigorova et al. 2011). Western blot analysis of heat-stable proteins (HSP90, SOD, CyPs, Aquaporins, LEA and WGA) revealed that these proteins were highly induced during combined heat and drought stress, as compared to individual stress, in both tolerant as well as susceptible genotypes of wheat (Triticum aestivum) (Rakhra and Sharma 2012). Various stress-responsive proteins responsible for heat, drought, and combined stress tolerance were also examined in two cultivars of Kentucky bluegrass (Poapratensis L.) viz. (tolerant 'Midnight' and sensitive 'Brilliant') (Xu and Huang 2012). Physiological assays showed that 'Midnight' cultivar showed high photochemical efficiency and relative leaf water content and less membrane damage in comparison with 'brilliant' during all stress treatments (Xu and Huang 2012) under combined stresses. Moreover, some novel proteins responsive to these stresses, especially heat shock proteins (HSPs70 and HSPs90), were highly induced, whereas proteins related to photorespiration were downregulated (Xu and Huang 2012). Under drought stress, only chaperonins were upregulated in both the cultivars, while GAPDH (glyceraldehydes-3-phosphate dehydrogenase) was exclusively expressed during combined stress, whereas heat shock proteins (HSPs70 and HSPs90) were upregulated under heat stress (Xu and Huang 2012). In barley, differential regulation of leaf proteins in response to heat, drought and combination of both suggested variations in the role of these proteins in detoxification, photosynthesis, protein biosynthesis and energy metabolism (Rollins et al. 2013). Leaf proteomic analysis of barley plants showed no significant change in protein abundance under drought stress, whereas during heat stress, a large number of proteins associated with light-harvesting complex (Lhcb3) and the oxygen-evolving complexes (PsbO and PsbP) were upregulated, whereas these were enhanced by tenfold in combined drought/heat treatment (Rollins et al. 2013). Some novel transcripts, such as MYB78 and ATAF1, stress chaperones, viz. heat shock proteins (HSPs), were highly expressed in sorghum plants, exposed to heat, drought, and combination of both; and functional characterization of these proteins in response to these stresses was proposed to enhance stress tolerance (Johnson et al. 2014).

Proteome analysis showed that during drought stress, highly activated LEA (late embryogenesis abundant), HKT1, a sodium ion transmembrane transporter proteins, engaged in cellular $\mathrm{Na}+$ homeostasis maintenance, and P5CS2 (Delta-1-pyrroline-5-carboxylate synthase, involved in proline synthesis) were expressed, whereas during heat stress, expression of large number of heat shock proteins was prominent (Johnson et al. 2014). Moreover, in combined stress, some unique genes related to protein ubiquitination and aromatic compound metabolism, glutathione transferases, heat shock proteins, and senescence-associated genes were highly expressed (Johnson et al. 2014). In maize, the expression level of 
Table 2 Stress-related proteins of different types having strong potential for developing drought and heat tolerant plants, on the basis of experimental evidences, obtained from various field-grown transgenic plants, under controlled environment

\begin{tabular}{|c|c|c|c|c|}
\hline Stress protein/type & Transgenic plant & Stress & Criteria & References \\
\hline OsPYL3/ABA receptor & Rice & Drought & $\begin{array}{l}\text { Higher relative leaf water content, chlorophyll, fresh, and dry } \\
\text { weight accumulation at maturity under stress }\end{array}$ & Lenka et al. (2018) \\
\hline SNAC1/NAC TF & Rice & Drought & $\begin{array}{l}\text { Higher seed setting, higher osmotic adjustment, cell mem- } \\
\text { brane stability, protection of important macromolecules } \\
\text { from degradation, and maintenance of redox homeostasis } \\
\text { and detoxification under stress }\end{array}$ & Hu et al. (2006) \\
\hline GbMYB5/MYB TF & Cotton & Drought & $\begin{array}{l}\text { Enhanced root architecture, root expansion, increase in water- } \\
\text { use efficiency (WUE) and biomass, multiple stress tolerance } \\
\text { without yield penalty under stress }\end{array}$ & Chen et al. $(2015 \mathrm{a}, \mathrm{b})$ \\
\hline TaABL1/TF & Wheat & Drought/heat & $\begin{array}{l}\text { Hastened stomatal closure, oxidative tolerance under stress, } \\
\text { thereby improving tolerance to multiple abiotic stresses. } \\
\text { Up- or down-regulation of expression of some stress-related } \\
\text { genes controlling stomatal closure under drought stress }\end{array}$ & Xu et al. (2014a) \\
\hline OSMSD1/HSP & Rice & Heat & $\begin{array}{l}\text { Oxidative tolerance increased chaperone generation and regu- } \\
\text { lation of quality control systems in grains under heat stress }\end{array}$ & Shiraya et al. (2015) \\
\hline
\end{tabular}

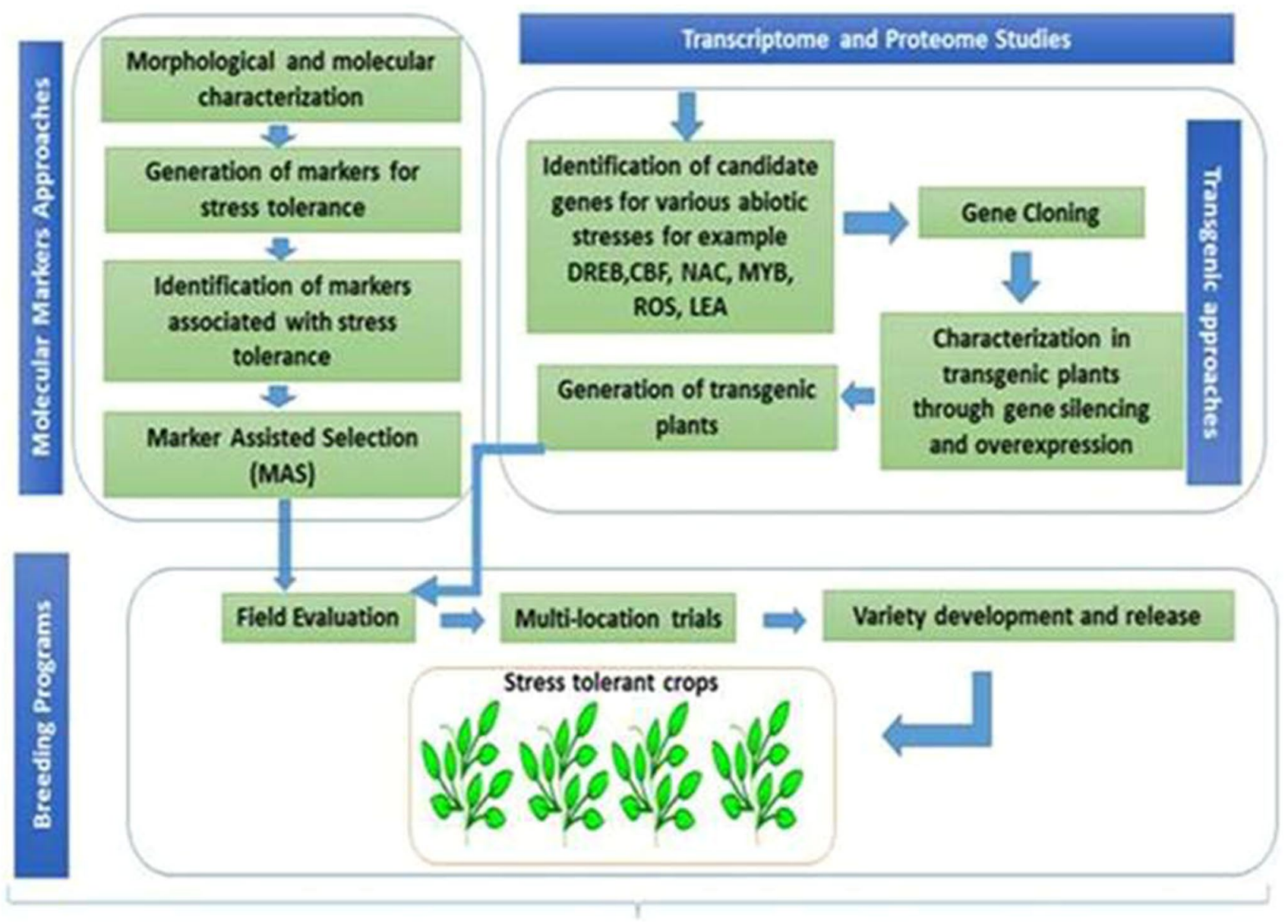

Fig. 3 Combined approach for developing drought or/and heat stress-tolerant plants 
different proteins was changed significantly under combination of heat and drought (Zhao et al. 2016). The upregulation of 16,28 , and 61 proteins was peculiar to drought stress, whereas 65,135 , and 201 proteins were differentially expressed under both heat, drought as well as combined stresses, respectively (Zhao et al. 2016). In another study in maize (Hu et al. 2015), three sHSP (B4G250, BF976 B6T649) were highly expressed under heat and combined heat/drought; however, no significant change in these proteins was noticed under drought stress. Recent studies confirmed that ABA is responsible for tailored response of plants to the co-occurring drought and heat stress as well as individually applied heat or drought stress (Suzuki 2016). For instance, enhanced accumulation of 9-cis epoxycarotenoid dioxygenase (NCED) protein involved in ABA biosynthesis was highly expressed in poplar in response to drought or heat stress alone $(\mathrm{Li}$ et al. 2014a, b, c). However, under the stress combination, in contrast, NCED protein accumulation initially enhanced then declined, suggesting the different regulatory mechanisms of ABA under these single and combined stresses ( Li et al. 2014a, b, c).

Likewise, the combined as well as individual effects of drought and heat stress were compared in the leaves of two soya bean cultivars, viz. Surge and Davison, through various physiological and biochemical assays (Das et al. 2016). The study revealed that a wide array of abiotic stress-related proteins regulating different signaling pathways and molecular events were expressed differentially under these stresses (Das et al. 2016). The heat shock protein 70 and EF-Tu protein were highly upregulated during heat stress, whereas no such enhancement under drought stress was observed in both the cultivars (Das et al. 2016).

Taken together, above findings showed the crucial and distinctive involvement of various stress-responsive proteins in response to heat, drought, as well as their combination, suggesting unique cellular defense responses; however, detailed mechanism of pathways and genesassociated individual and combined stresses are largely unknown and need to be probed further.

\section{Conclusion and future perspective}

This review emphasizes the promising roles of different stress proteins as a tool to enhance plant responses to drought and heat stress in various model and agricultural crops. The abiotic stress response is a complex process in plants because of the involvement of many gene families and their complex interactions. Stress proteins have been well established to participate in stress tolerance, and approaches of overexpressing these genes in model plants under controlled conditions have been quite successful, as described in Table 1. However, signal specificity is achieved as a result of the interplay between components of the various pathways, particularly the hormones such as ABA, TFs, HSFs, and ROS, etc. The major objectives of the current plant stress research are to deliver specific targets for the improvement of stress resistance in agricultural crops. This review presents some important regulatory genes that act in drought and heat stress response systems, individually, as well as in combination. Though various studies have reported numerous proteins associated with drought and/or heat, few of them seem to have a strong potential in improving tolerance against these stresses, as evidenced by the performance of transgenic plants overexpressing them, under controlled field environment (Table 2). These plants have been evaluated on the basis of several criteria/traits related to drought or heat tolerance (Table 2) and may hold promise for future applications in crop improvement. Manipulation of these genes may confer tolerance to drought and heat, along with other stresses too, in various food crops. In future, to have a specific model for crop stress responses, a combined approach should be implemented through the alignment of research on abiotic stress proteins with other omics technologies such as proteomics, transcriptomics, genomics, and metabolomics (Fig. 3). During the past years, the need for a change in the attention in abiotic stress research has become obvious. There is also a dearth of studies focusing on the negative effect of overexpression of TFs on flowering time and yield in agricultural crops. A lot of statistics about stress proteins have been collected in response to drought and heat stress. However, a complete regulatory mechanism of individual transcription factors and their interactions remains mostly unidentified, which is required to obtain the favorable TF-related genes for breeding abiotic stress-tolerant crops with improved yield. Therefore, it is still a significant challenge for researchers to figure out a complete understanding of the detailed regulatory mechanisms for abiotic stress responses emphasizing drought and heat for breeding multiple stress-tolerant crops with increased yields and better qualities. Considering the future scenario, more emphasis would be needed in probing the unique proteins associated with combined heat and drought stress tolerance in various agricultural crops.

Author contribution statement $\mathrm{HN}$ envisaged the concept, MP compiled all the literature, and HN and MP wrote the article. SP and SS added recent information on various proteins. Rest of the authors thoroughly edited and added information for various categories of proteins.

Acknowledgements The first author (MP) is thankful to CSIR-UGC, New Delhi, India, for financial support in the form of a fellowship. The 
corresponding author is thankful to DST, New Delhi, for PURSE grants and University of Western Australia, Australia, for financial support.

\section{Compliance with ethical standards}

Conflict of interest The authors declare that they have no conflict of interest.

\section{References}

Aharon R, Shahak Y, Wininger S et al (2003) Overexpression of a plasma membrane aquaporin in transgenic tobacco improves plant vigor under favorable growth conditions but not under drought or salt stress. Plant Cell 15:439-447

Aliprantis AO, Yang R-B, Mark MR et al (1999) Cell activation and apoptosis by bacterial lipoproteins through toll-like receptor-2 . Science 285:736-739

Allagulova CR, Gimalov FR, Shakirova FM, Vakhitov VA (2003) The plant dehydrins: structure and putative functions. Biochem 68:945-951

Alsheikh MK, Svensson JT, Randall SK (2005) Phosphorylation regulated ion-binding is a property shared by the acidic subclass dehydrins. Plant, \Cell Environ 28:1114-1122

Amara I, Zaidi I, Masmoudi K et al (2014) Insights into late embryogenesis abundant (LEA) proteins in plants: from structure to the functions. Am J Plant Sci 5:3440

Anil Kumar S, Hima Kumari P, Shravan Kumar G et al (2015) Osmotin: a plant sentinel and a possible agonist of mammalian adiponectin. Front Plant Sci 6:163

Arbona V, Manzi M, Zandalinas SI et al (2017) Physiological, metabolic, and molecular responses of plants to abiotic stress. In: Sarwat M, Ahmad A, Abdin M, Ibrahim M (eds) Stress signaling in plants: genomics and proteomics perspective, vol 2. Springer, Cham, pp 1-35

Asano T, Hayashi N, Kikuchi S, Ohsugi R (2012) CDPK-mediated abiotic stress signaling. Plant Signal Behav 7:817-821

Aslam M, Singh R, Anandhan S et al (2009) Development of a transformation protocol for Tecomella undulata (Smith) Seem from cotyledonary node explants. Sci Hortic (Amsterdam) 121:119-121

Atkinson NJ, Urwin PE (2012) The interaction of plant biotic and abiotic stresses: from genes to the field. J Exp Bot 63:3523-3543

Awasthi R, Bhandari K, Nayyar H (2015) Temperature stress and redox homeostasis in agricultural crops. Front Environ Sci 3:1-24

Awasthi R, Gaur P, Turner NC et al (2017) Effects of individual and combined heat and drought stress during seed filling on the oxidative metabolism and yield of chickpea (Cicer arietinum) genotypes differing in heat and drought tolerance. Crop Pasture Sci 68:823-841

Bakshi M, Oelmüller R (2014) WRKY transcription factors: jack of many trades in plants. Plant signal Behav 9:e27700

Balakrishnan H, Gajjeraman P, Pattiwala YU (2016) Molecular cloning and expression analysis of MYB-related transcription factor gene, ScMYB76 from sugarcane (Saccharum hybrid). Indian J Sci Technol 9:1-10

Baldoni E, Genga A, Cominelli E (2015) Plant MYB transcription factors: their role in drought response mechanisms. Int J Mol Sci 116:15811-15851

Baloglu MC, Eldem V, Hajyzadeh M, Unver T (2014) Genome-wide analysis of the bZIP transcription factors in cucumber. PLoS ONE 9:e96014
Banerjee A, Roychoudhury A (2015) WRKY proteins: signaling and regulation of expression during abiotic stress responses. Sci World J 15:1-17

Banerjee A, Roychoudhury A (2016) Group II late embryogenesis abundant (LEA) proteins: structural and functional aspects in plant abiotic stress. Plant Growth Regul 79:1-17

Baniwal SK, Bharti K, Chan KY et al (2004) Heat stress response in plants: a complex game with chaperones and more than twenty heat stress transcription factors. J Biosci 29:471-487

Bao F, Du D, An Y et al (2017) Overexpression of Prunus mume dehydrin genes in tobacco enhances tolerance to cold and drought. Front Plant Sci 8:15

Barnabás B, Jäger K, Fehér A (2008) The effect of drought and heat stress on reproductive processes in cereals. Plant Cell Environ 31:11-38

Battaglia M, Covarrubias AA (2013) Late embryogenesis abundant (LEA) proteins in legumes. Front Plant Sci 4:19

Battaglia M, Olvera-Carrillo Y, Garciarrubio A et al (2008) The enigmatic LEA proteins and other hydrophilins. Plant Physiol 148:6-24

Bauer H, Ache P, Lautner S et al (2013) The stomatal response to reduced relative humidity requires guard cell-autonomous $\mathrm{ABA}$ synthesis. Curr Biol 23:53-57

Ben Saad R, Fabre D, Mieulet D et al (2012) Expression of the Aeluropus littoralis AlSAP gene in rice confers broad tolerance to abiotic stresses through maintenance of photosynthesis. Plant Cell Environ 35:626-643

Berriri S, Garcia AV, dit Frey NF (2012) Constitutively active mitogenactivated protein kinase versions reveal functions of Arabidopsis MPK4 in pathogen defense signaling. Plant Cell 24:4281-4293

Blanco FA, Zanetti ME, Casalongué CA, Daleo GR (2006) Molecular characterization of a potato MAP kinase transcriptionally regulated by multiple environmental stresses. Plant Physiol Biochem 44:315-322

Bobbert T, Rochlitz H, Wegewitz U et al (2005) Changes of adiponectin oligomer composition by moderate weight reduction. Diabetes 54:2712-2719

Boudsocq M, Sheen J (2013) CDPKs in immune and stress signaling. Trends Plant Sci 18:30-40

Boyer JS, Byrne P, Cassman KG et al (2013) The US drought of 2012 in perspective: a call to action. Glob Food Secur 2:139-143

Bredow M, Vanderbeld B, Walker VK (2017) Ice-binding proteins confer freezing tolerance in transgenic Arabidopsis thaliana. Plant Biotechnol J 15:68-81

Bundó M, Coca M (2017) Calcium-dependent protein kinase OsCPK10 mediates both drought tolerance and blast disease resistance in rice plants. J Exp Bot 68:2963-2975

Campo S, Baldrich P, Messeguer J et al (2014) Overexpression of a calcium-dependent protein kinase confers salt and drought tolerance in rice by preventing membrane lipid peroxidation. Plant Physiol 165:688-704

Chaumont F, Tyerman SD (2014) Aquaporins: highly regulated channels controlling plant water relations. Plant Physiol 164:1600-1618

Chen J-G, Willard FS, Huang J et al (2003) A seven-transmembrane RGS protein that modulates plant cell proliferation. Science 301:1728-1731

Chen L, Ren F, Zhou L et al (2012) The Brassica napus calcineurin B-Like 1/CBL-interacting protein kinase 6 (CBL1/CIPK6) component is involved in the plant response to abiotic stress and ABA signalling. J Exp Bot 63:6211-6222

Chen T, Li W, Hu X et al (2015a) A cotton MYB transcription factor, GbMYB5, is positively involved in plant adaptive response to drought stress. Plant Cell Physiol 56:917-929 
Chen Y, Lo S, Sun P et al (2015b) A late embryogenesis abundant protein HVA1 regulated by an inducible promoter enhances root growth and abiotic stress tolerance in rice without yield penalty. Plant Biotechnol J 13:105-116

Chen H, Liu L, Wang L et al (2016) VrDREB2A, a DREB-binding transcription factor from Vigna radiata, increased drought and high-salt tolerance in transgenic Arabidopsis thaliana. J Plant Res 129:263-273

Chen J, Nolan TM, Ye H et al (2017) Arabidopsis WRKY46, WRKY54, and WRKY70 transcription factors are involved in brassinosteroid-regulated plant growth and drought responses. Plant Cell 29:1425-1439

Chew YH, Halliday KJ (2011) A stress-free walk from Arabidopsis to crops. Curr Opin Biotechnol 22:281-286

Choudhury SR, Bisht NC, Thompson R et al (2011) Conventional and novel $\mathrm{G} \gamma$ protein families constitute the heterotrimeric G-protein signaling network in soybean. PLoS ONE 6:e23361

Chowdhury S, Basu A, Kundu S (2017) Overexpression of a new osmotin-like protein gene (SindOLP) confers tolerance against biotic and abiotic stresses in sesame. Front Plant Sci 8:410

Chu X, Wang C, Chen X et al (2015) The cotton WRKY gene GhWRKY41 positively regulates salt and drought stress tolerance in transgenic Nicotiana benthamiana. PLoS ONE 10:e0143022

Cristina MS, Petersen M, Mundy J (2010) Mitogen-activated protein kinase signaling in plants. Annu Rev Plant Biol 61:621-649

Dai F, Zhang C, Jiang X et al (2012) RhNAC2 and RhEXPA4 are involved in regulation of dehydration tolerance during the expansion of rose petals. Plant Physiol 160:112

Dalal M, Chinnusamy V (2015) ABA receptors: prospects for enhancing biotic and abiotic stress tolerance of crops. In: Pandey G (ed) Elucidation of abiotic stress signaling in plants. Springer, New York, NY, pp 271-298

Danquah A, de Zelicourt A, Colcombet J, Hirt H (2014) The role of ABA and MAPK signaling pathways in plant abiotic stress responses. Biotechnol Adv 32:40-52

Dansana PK, Kothari KS, Vij S, Tyagi AK (2014) OsiSAP1 overexpression improves water-deficit stress tolerance in transgenic rice by affecting expression of endogenous stress-related genes. Plant Cell Rep 33:1425-1440

Das S, Chakraborty S (2016) The role of osmotin protein tolerance to biotic and abiotic stress in plants. Int J Bioinform Biol Sci 4:35

Das M, Chauhan H, Chhibbar A et al (2011) High-efficiency transformation and selective tolerance against biotic and abiotic stress in mulberry, Morus indica cv. K2, by constitutive and inducible expression of tobacco osmotin. Transgenic Res 20:231-246

Das A, Eldakak M, Paudel B et al (2016) Leaf proteome analysis reveals prospective drought and heat stress response mechanisms in soybean. Biomed Res Int 2016:6021047. https://doi. org/10.1155/2016/6021047

Daszkowska-Golec A, Szarejko I (2013) Open or close the gate-stomata action under the control of phytohormones in drought stress conditions. Front Plant Sci 4:138

De Boeck HJ, Bassin S, Verlinden M et al (2016) Simulated heat waves affected alpine grassland only in combination with drought. New Phytol 209:531-541

de Zelicourt A, Colcombet J, Hirt H (2016) The role of MAPK modules and ABA during abiotic stress signaling. Trends Plant Sci 21:677-685

Deng L-Q, Yu H-Q, Liu Y-P et al (2014) Heterologous expression of antifreeze protein gene AnAFP from Ammopiptanthus nanus enhances cold tolerance in Escherichia coli and tobacco. Gene 539:132-140

Deshmukh RK, Sonah H, Bélanger RR (2016) Plant Aquaporins: genome-wide identification, transcriptomics, proteomics, and advanced analytical tools. Front Plant Sci 7:1896
Desikan R, Horák J, Chaban C et al (2008) The histidine kinase AHK5 integrates endogenous and environmental signals in Arabidopsis guard cells. PLoS ONE 3:e2491

Ding X, Iwasaki I, Kitagawa Y (2004) Overexpression of a lily PIP1 gene in tobacco increased the osmotic water permeability of leaf cells. Plant Cell Environ 27:177-186

Dixit AR, Dhankher OP (2011) A novel stress-associated protein “AtSAP10" from Arabidopsis thaliana confers tolerance to nickel, manganese, zinc, and high temperature stress. PLoS ONE 6:e20921

Dixit A, Tomar P, Vaine E et al (2017) A stress-associated protein, AtSAP13, from Arabidopsis thaliana provides tolerance to multiple abiotic stresses. Plant Cell Environ 41:1171-1185

Du H, Huang M, Zhang Z, Cheng S (2014) Genome-wide analysis of the AP2/ERF gene family in maize waterlogging stress response. Euphytica 198:115-126

Duan J, Cai W (2012) OsLEA3-2, an abiotic stress induced gene of rice plays a key role in salt and drought tolerance. PLoS ONE 7:e45117

Dubrovina AS, Kiselev KV, Khristenko VS, Aleynova OA (2015) VaCPK20, a calcium-dependent protein kinase gene of wild grapevine Vitis amurensis Rupr., mediates cold and drought stress tolerance. J Plant Physiol 185:1-12

Dubrovina AS, Aleynova OA, Kiselev KV (2016) Influence of overexpression of the true and false alternative transcripts of calcium-dependent protein kinase CPK9 and CPK3a genes on the growth, stress tolerance, and resveratrol content in Vitis amurensis cell cultures. Acta Physiol Plant 38:78

Dure L III, Greenway SC, Galau GA (1981) Developmental biochemistry of cottonseed embryogenesis and germination: changing messenger ribonucleic acid populations as shown by in vitro and in vivo protein synthesis. Biochemistry 20:4162-4168

Eriksson SK, Harryson P (2011) Dehydrins: molecular biology, structure and function. In: Lüttge U, Beck E, Bartels D (eds) Plant desiccation tolerance. Ecological studies (analysis and synthesis), vol 215. Springer, Berlin, pp 289-305

Eriksson S, Eremina N, Barth A et al (2016) Membrane-induced folding of the plant-stress protein Lti30. Plant Physiol 71:932-943

Fahad S, Bajwa AA, Nazir U et al (2017) Crop production under drought and heat stress: plant responses and management options. Front Plant Sci 8:1147

Fan X, Guo Q, Xu P et al (2015) Transcriptome-wide identification of salt-responsive members of the WRKY gene family in Gossypium aridum. PLoS ONE 10:e0126148

Fang Y, Liao K, Du H et al (2015) A stress-responsive NAC transcription factor SNAC3 confers heat and drought tolerance through modulation of reactive oxygen species in rice. J Exp Bot 66:6803-6817

Feng L, Gao Z, Xiao G et al (2014) Leucine-rich repeat receptor-like kinase FON1 regulates drought stress and seed germination by activating the expression of ABA-responsive genes in rice. Plant Mol Biol Rep 32:1158-1168

Feng W, Kita D, Peaucelle A et al (2018) The FERONIA receptor kinase maintains cell-wall integrity during salt stress through $\mathrm{Ca}^{2+}$ signaling. Curr Biol 28:666-675

Ferreira PC, Hemerly AS, Villarroel R et al (1991) The Arabidopsis functional homolog of the $\mathrm{p} 34 \mathrm{cdc} 2$ protein kinase. Plant Cell 3:531-540

Gao J, Lan T (2016) Functional characterization of the late embryogenesis abundant (LEA) protein gene family from Pinus tabuliformis (Pinaceae) in Escherichia coli. Sci Rep 6:19467

Gao F, Yao H, Zhao H et al (2016) Tartary buckwheat FtMYB10 encodes an R2R3-MYB transcription factor that acts as a novel negative regulator of salt and drought response in transgenic Arabidopsis. Plant Physiol Biochem 109:387-396 
Geiger D, Scherzer S, Mumm P et al (2009) Activity of guard cell anion channel SLAC1 is controlled by drought-stress signaling kinase-phosphatase pair. Proc Natl Acad Sci 106:21425-21430

Ghneim-Herrera T, Selvaraj MG, Meynard D et al (2017) Expression of the Aeluropus littoralis AlSAP gene enhances rice yield under field drought at the reproductive stage. Front Plant Sci 8:994

Gill SS, Tuteja N (2010) Reactive oxygen species and antioxidant machinery in abiotic stress tolerance in crop plants. Plant Physiol Biochem 48:909-930

Giri J, Vij S, Dansana PK, Tyagi AK (2011) Rice A20/AN1 zinc-finger containing stress-associated proteins (SAP1/11) and a receptorlike cytoplasmic kinase (OsRLCK253) interact via A20 zinc-finger and confer abiotic stress tolerance in transgenic Arabidopsis plants. New Phytol 191:721-732

Giri J, Dansana PK, Kothari KS et al (2013) SAPs as novel regulators of abiotic stress response in plants. BioEssays 35:639-648

Goswami S, Kumar RR, Sharma SK et al (2015) Calcium triggers protein kinases-induced signal transduction for augmenting the thermotolerance of developing wheat (Triticum aestivum) grain under the heat stress. J Plant Biochem Biotechnol 24:441-452

Graether SP, Boddington KF (2014) Disorder and function: a review of the dehydrin protein family. Front Plant Sci 5:576

Greeff CCG, Roux MMR, Mundy JJM, Petersen MMP (2012) Receptor-like kinase complexes in plant innate immunity. Front Plant Sci 3:209

Grigorova B, Vaseva I, Demirevska K, Feller U (2011) Combined drought and heat stress in wheat: changes in some heat shock proteins. Biol Plant 55:105-111

Gu Z, Ma B, Jiang Y et al (2008) Expression analysis of the calcineurin B-like gene family in rice (Oryza sativa $\mathrm{L}$.) under environmental stresses. Gene 415:1-12

Gu C, Guo Z-H, Hao P-P et al (2017) Multiple regulatory roles of AP2/ ERF transcription factor in angiosperm. Bot Stud 58:6

Guerra D, Crosatti C, Khoshro HH et al (2015) Post-transcriptional and post-translational regulations of drought and heat response in plants: a spider's web of mechanisms. Front Plant Sci 6:57

Guo Y, Gan S (2006) AtNAP, a NAC family transcription factor, has an important role in leaf senescence. Plant J 46:601-612

Guo M, Liu J-H, Ma X et al (2016) The plant heat stress transcription factors (HSFs): structure, regulation, and function in response to abiotic stresses. Front Plant Sci 7:114

Guo X, Zhang L, Zhu J et al (2017) Cloning and characterization of SiDHN, a novel dehydrin gene from Saussurea involucrata Kar. et Kir. that enhances cold and drought tolerance in tobacco. Plant Sci 256:160-169

Ha S, Vankova R, Yamaguchi-Shinozaki K et al (2012) Cytokinins: metabolism and function in plant adaptation to environmental stresses. Trends Plant Sci 17:172-179

Hanin M, Brini F, Ebel C et al (2011) Plant dehydrins and stress tolerance: versatile proteins for complex mechanisms. Plant Signal Behav 6:1503-1509

Hao Y, Wei W, Song Q et al (2011) Soybean NAC transcription factors promote abiotic stress tolerance and lateral root formation in transgenic plants. Plant J 68:302-313

Hashimoto K, Eckert C, Anschütz U et al (2012) Phosphorylation of calcineurin B-like (CBL) calcium sensor proteins by their CBL-interacting protein kinases (CIPKs) is required for full activity of CBL-CIPK complexes toward their target proteins. J Biol Chem 287:7956-7968

He L, Yang X, Wang L et al (2013) Molecular cloning and functional characterization of a novel cotton CBL-interacting protein kinase gene (GhCIPK6) reveals its involvement in multiple abiotic stress tolerance in transgenic plants. Biochem Biophys Res Commun 435:209-215

He G-H, Xu J-Y, Wang Y-X et al (2016) Drought-responsive WRKY transcription factor genes TaWRKY1 and TaWRKY33 from wheat confer drought and/or heat resistance in Arabidopsis. BMC Plant Biol 16:116

He Z, Zhong J, Sun X et al (2018) The maize ABA receptors ZmPYL8, 9, and 12 facilitate plant drought resistance. Front Plant Sci 9:422

Hettenhausen C, Sun G, He Y et al (2016) Genome-wide identification of calcium-dependent protein kinases in soybean and analyses of their transcriptional responses to insect herbivory and drought stress. Sci Rep 6:18973

Hines P (2009) ABA receptor up close. Sci Signal 2:ec391

Hong JK, Jung HW, Lee BK et al (2004) An osmotin-like protein gene, CAOSM1, from pepper: differential expression and in situ localization of its mRNA during pathogen infection and abiotic stress. Physiol Mol Plant Pathol 64:301-310

Hong Y, Zhang H, Huang L et al (2016) Overexpression of a stressresponsive NAC transcription factor gene ONAC022 improves drought and salt tolerance in rice. Front Plant Sci 7:4

Hu HH, Dai MQ, Yao JL et al (2006) Overexpressing a NAM, ATAF, and CUC (NAC) transcription factor enhances drought resistance and salt tolerance in rice. Proc Natl Acad Sci USA 103:12987-12992

$\mathrm{Hu}$ R, Qi G, Kong Y et al (2010) Comprehensive analysis of NAC domain transcription factor gene family in Populus trichocarpa. BMC Plant Biol 10:145

Hu X, Yang Y, Gong F et al (2015) Protein sHSP26 improves chloroplast performance under heat stress by interacting with specific chloroplast proteins in maize (Zea mays). J Proteomics 115:81-92

Hu SB, Zhou Q, An J, Yu BJ (2016a) Cloning PIP genes in droughttolerant vetiver grass and responses of transgenic VzPIP2; 1 soybean plants to water stress. Biol Plant 60:655-666

$\mathrm{Hu}$ T, Zhu S, Tan L et al (2016b) Overexpression of OsLEA4 enhances drought, high salt and heavy metal stress tolerance in transgenic rice (Oryza sativa L.). Environ Exp Bot 123:68-77

$\mathrm{Hu}$ W, Yang H, Yan Y et al (2016c) Genome-wide characterization and analysis of bZIP transcription factor gene family related to abiotic stress in cassava. Sci Rep 6:22783

Huang J, Wang M-M, Jiang Y et al (2008) Expression analysis of rice A20/AN1-type zinc finger genes and characterization of ZFP177 that contributes to temperature stress tolerance. Gene 420:135-144

Huang L, Wang Y, Wang W et al (2018) Characterization of transcription factor gene OsDRAP1 conferring drought tolerance in rice. Front Plant Sci 209:94

Hughes SL, Schart V, Malcolmson J et al (2013) The importance of size and disorder in the cryoprotective effects of dehydrins. Plant Physiol 163:1376-1386

Hundertmark M, Hincha DK (2008) LEA (late embryogenesis abundant) proteins and their encoding genes in Arabidopsis thaliana. BMC Genom 9:118

Husaini AM, Abdin MZ (2008) Overexpression of tobacco osmotin gene leads to salt stress tolerance in strawberry (Fragaria $\times$ ananassa Duch.) plants. Indian J Biotechnol 7:465-471

Ingram J, Bartels D (1996) The molecular basis of dehydration tolerance in plants. Annu Rev Plant Biol 47:377-403

Ismail AM, Hall AE, Close TJ (1999) Purification and partial characterization of a dehydrin involved in chilling tolerance during seedling emergence of cowpea. Plant Physiol 120:237-244

Javot H, Maurel C (2002) The role of aquaporins in root water uptake. Ann Bot 90:301-313

Jensen MK, Kjaersgaard T, Nielsen MM et al (2010) The Arabidopsis thaliana NAC transcription factor family: structure-function relationships and determinants of ANAC019 stress signalling. Biochem J 426:183-196 
Jia H, Wang C, Wang F et al (2015) GhWRKY68 reduces resistance to salt and drought in transgenic Nicotiana benthamiana. PLoS ONE 10:e0120646

Jiang J, Ma S, Ye N et al (2017) WRKY transcription factors in plant responses to stresses. J Integr Plant Biol 59:86-101

Jiménez JÁ, Alonso-Ramírez A, Nicolás C (2008) Two cDNA clones (FsDhn1 and FsClo1) up-regulated by ABA are involved in drought responses in Fagus sylvatica L. seeds. J Plant Physiol 165:1798-1807

Johnson SM, Lim F-L, Finkler A et al (2014) Transcriptomic analysis of Sorghum bicolor responding to combined heat and drought stress. BMC Genom 15:456

Jones HG (2006) Monitoring plant and soil water status: established and novel methods revisited and their relevance to studies of drought tolerance. J Exp Bot 58:119-130

Joshi RK, Kar B, Nayak S (2011) Characterization of mitogen activated protein kinases (MAPKs) in the Curcuma longa expressed sequence tag database. Bioinformation 7:180

Joshi R, Singla-Pareek SL, Pareek A (2018) Engineering abiotic stress response in plants for biomass production. J Biol Chem 293:5035-5043

Joshi-Saha A, Valon C, Leung J (2011) A brand new START: abscisic acid perception and transduction in the guard cell. Sci Signal 4:re4

Kaldenhoff R, Fischer M (2006) Aquaporins in plants. Acta Physiol 187:169-176

Kanneganti V, Gupta AK (2008) Overexpression of OsiSAP8, a member of stress associated protein (SAP) gene family of rice confers tolerance to salt, drought and cold stress in transgenic tobacco and rice. Plant Mol Biol 66:445-462

Katiyar-Agarwal S, Agarwal M, Grover A (2003) Heat-tolerant basmati rice engineered by over-expression of hsp101. Plant Mol Biol 51:677-686

Kaur H, Petla BP, Kamble NU et al (2015) Differentially expressed seed aging responsive heat shock protein OsHSP18. 2 implicates in seed vigor, longevity and improves germination and seedling establishment under abiotic stress. Front Plant Sci 14:713

Khan MS, Ahmad D, Khan MA (2015) Utilization of genes encoding osmoprotectants in transgenic plants for enhanced abiotic stress tolerance. Electron J Biotechnol 18:257-266

Kharte SB, Watharkar AD, Shingote PR et al (2016) Functional characterization and expression study of sugarcane MYB transcription factor gene PEaMYBAS1 promoter from Erianthus arundinaceus that confers abiotic stress tolerance in tobacco. RSC Adv 6:19576-19586

Kim K-N, Cheong YH, Grant JJ et al (2003) CIPK3, a calcium sensor-associated protein kinase that regulates abscisic acid and cold signal transduction in Arabidopsis. Plant Cell 15:411-423

Kim H, Lee K, Hwang H et al (2014) Overexpression of PYL5 in rice enhances drought tolerance, inhibits growth, and modulates gene expression. J Exp Bot 65:453-464

Kline KG, Sussman MR, Jones AM (2010) Abscisic acid receptors. Plant Physiol 154:479-482

Kosová K, Vítámvás P, Prášil IT (2014) Wheat and barley dehydrins under cold, drought, and salinity-what can LEA-II proteins tell us about plant stress response? Front Plant Sci 5:343

Kotak S, Port M, Ganguli A et al (2004) Characterization of C-terminal domains of Arabidopsis heat stress transcription factors (Hsfs) and identification of a new signature combination of plant class A Hsfs with AHA and NES motifs essential for activator function and intracellular localization. Plant J 39:98-112

Kotak S, Larkindale J, Lee U et al (2007) Complexity of the heat stress response in plants. Curr Opin Plant Biol 10:310-316

Kothari KS, Dansana PK, Giri J, Tyagi AK (2016) Rice stress associated protein 1 (OsSAP1) interacts with aminotransferase
(OsAMTR1) and pathogenesis-related 1a protein (OsSCP) and regulates abiotic stress responses. Front Plant Sci 7:1057

Kovacs D, Agoston B, Tompa P (2008a) Disordered plant LEA proteins as molecular chaperones. Plant Signal Behav 3:710-713

Kovacs D, Kalmar E, Torok Z, Tompa P (2008b) Chaperone activity of ERD10 and ERD14, two disordered stress-related plant proteins. Plant Physiol 147:381-390

Kozłowska M, Rybus-Zajac M, Stachowiak J, Janowska B (2007) Changes in carbohydrate contents of Zantedeschia leaves under gibberellin-stimulated flowering. Acta Physiol Plant 29:27-32

Kregel KC (2002) Invited review: heat shock proteins: modifying factors in physiological stress responses and acquired thermotolerance. J Appl Physiol 92:2177-2186

Król A (2013) The growth and water uptake by yellow seed and black seed rape depending on the state of soil compaction. Dissertation. Bohdan Dobrzañski Institute of Agrophysics PAS, Lublin

Kudla J, Batistič O, Hashimoto K (2010) Calcium signals: the lead currency of plant information processing. Plant Cell 22:541-563

Kumar RR, Goswami S, Sharma SK et al (2012) Protection against heat stress in wheat involves change in cell membrane stability, antioxidant enzymes, osmolyte, $\mathrm{H}_{2} \mathrm{O}_{2}$ and transcript of heat shock protein. Int J Plant Physiol Biochem 4:83-91

Kumar MN, Jane W-N, Verslues PE (2013) Role of the putative osmosensor Arabidopsis histidine kinase1 in dehydration avoidance and low-water-potential response. Plant Physiol 161:942-953

Kumar M, Lee SC, Kim JY et al (2014) Over-expression of dehydrin gene, OsDhn1, improves drought and salt stress tolerance through scavenging of reactive oxygen species in rice (Oryza sativa L.). J Plant Biol 57:383-393

Lakra N, Nutan KK, Das P et al (2015) A nuclear-localized histonegene binding protein from rice (OsHBP1b) functions in salinity and drought stress tolerance by maintaining chlorophyll content and improving the antioxidant machinery. J Plant Physiol $176: 36-46$

Lamaoui M, Jemo M, Datla R, Bekkaoui F (2018) Heat and drought stresses in crops and approaches for their mitigation. Front Chem $6: 1-14$

Lata C, Prasad M (2011) Role of DREBs in regulation of abiotic stress responses in plants. J Exp Bot 62:4731-4748

Lata C, Yadav A, Prasad M (2011) Role of plant transcription factors in abiotic stress tolerance. In: Shanker A, Venkatswarlu B (eds) Abiotic stress response in plants-physiological, biochemical and genetic perspectives. InTech, London, pp 1-31

Latif F, Ullah F, Mehmood S et al (2016) Effects of salicylic acid on growth and accumulation of phenolics in Zea mays L. under drought stress. Acta Agric Scand Sect B Soil Plant Sci 66:325-332

Latz A, Mehlmer N, Zapf S et al (2013) Salt stress triggers phosphorylation of the Arabidopsis vacuolar K+ channel TPK1 by calciumdependent protein kinases (CDPKs). Mol Plant 6:1274-1289

Laur J, Hacke UG (2014) The role of water channel proteins in facilitating recovery of leaf hydraulic conductance from water stress in Populus trichocarpa. PLoS ONE 9:e111751

Le DT, Nishiyama RIE, Watanabe Y et al (2011) Genome-wide survey and expression analysis of the plant-specific NAC transcription factor family in soybean during development and dehydration stress. DNA Res 18:263-276

Le TTT, Williams B, Mundree SG (2018) An osmotin from the resurrection plant Tripogon loliiformis (TlOsm) confers tolerance to multiple abiotic stresses in transgenic rice. Physiol Plant 162:13-34

Lee S-C, Lee M-Y, Kim S-J et al (2005) Characterization of an abiotic stress-inducible dehydrin gene, OsDhn1, in rice (Oryza sativa L.). Mol Cells 19:1-8

Lee SC, Lan W, Buchanan BB, Luan S (2009) A protein kinasephosphatase pair interacts with an ion channel to regulate 
ABA signaling in plant guard cells. Proc Natl Acad Sci 106:21419-21424

Lee K-W, Rahman M, Choi GJ et al (2017) Expression of small heat shock protein 23 enhanced heat stress tolerance in transgenic ALFALFA plants. JAPS J Anim Plant Sci 27:1238-1244

Lenka SK, Muthusamy SK, Chinnusamy V, Bansal KC (2018) Ectopic expression of rice PYL3 enhances cold and drought tolerance in Arabidopsis thaliana. Mol Biotechnol 60:350-361

Lesk C, Rowhani P, Ramankutty N (2016) Influence of extreme weather disasters on global crop production. Nature 529:84

Li S, Fu Q, Chen L et al (2011) Arabidopsis thaliana WRKY25, WRKY26, and WRKY33 coordinate induction of plant thermotolerance. Planta 233:1237-1252

Li G, Santoni V, Maurel C (2014a) Plant aquaporins: roles in plant physiology. Biochim Biophys Acta (BBA)-Gen Subj 1840:1574-1582

Li X, Wu Y-L, Yang B et al (2014b) Function analysis of sugarcane A20/AN1 zinc-finger protein gene ShSAP1 in transgenic tobacco. Crop Sci 54:2724-2734

Li X, Yang Y, Sun X et al (2014c) Comparative physiological and proteomic analyses of poplar (Populus yunnanensis) plantlets exposed to high temperature and drought. PLoS ONE 9:e107605

Liang Q, Wu Y, Wang K et al (2017) Chrysanthemum WRKY gene DgWRKY5 enhances tolerance to salt stress in transgenic chrysanthemum. Sci Rep 7:4799

Liao Y, Jiang Y, Xu J et al (2017) Overexpression of a thylakoid membrane protein gene OsTMP14 improves indica rice cold tolerance. Biotechnol Biotechnol Equip 31:717-724

Liberek K, Lewandowska A, Ziętkiewicz S (2008) Chaperones in control of protein disaggregation. EMBO J 27:328-335

Licausi F, Ohme-Takagi M, Perata P (2013) APETALA2/ethylene responsive factor (AP2/ERF) transcription factors: mediators of stress responses and developmental programs. New Phytol 199:639-649

Liese A, Romeis T (2013) Biochemical regulation of in vivo function of plant calcium-dependent protein kinases (CDPK). Biochim Biophys Acta (BBA) Mol Cell Res 1833:1582-1589

Lim CW, Yang SH, Shin KH et al (2015) The AtLRK10L1. 2, Arabidopsis ortholog of wheat LRK10, is involved in ABA-mediated signaling and drought resistance. Plant Cell Rep 34:447-455

Lindemose S, O'Shea C, Jensen MK, Skriver K (2013) Structure, function and networks of transcription factors involved in abiotic stress responses. Int J Mol Sci 14:5842-5878

Ling H, Zeng X, Guo S (2016) Functional insights into the late embryogenesis abundant (LEA) protein family from Dendrobium officinale (Orchidaceae) using an Escherichia coli system. Sci Rep 6:39693

Link V, Sinha AK, Vashista P et al (2002) A heat-activated MAP kinase in tomato: a possible regulator of the heat stress response. FEBS Lett 531:179-183

Liu Y, Wang L, Xing X et al (2013) ZmLEA3, a multifunctional group 3 LEA protein from maize (Zea mays L.), is involved in biotic and abiotic stresses. Plant Cell Physiol 54:944-959

Liu H, Yu C, Li H et al (2015) Overexpression of ShDHN, a dehydrin gene from Solanum habrochaites enhances tolerance to multiple abiotic stresses in tomato. Plant Sci 231:198-211

Liu Y, Liang J, Sun L et al (2016) Group 3 LEA protein, ZmLEA3, is involved in protection from low temperature stress. Front Plant Sci 7:1011

Liu C, Wei C, Zhang M et al (2017) Mulberry MnMAPK1, a group $\mathrm{C}$ mitogen-activated protein kinase gene, endowed transgenic Arabidopsis with novel responses to various abiotic stresses. Plant Cell Tissue Organ Cult 131:151-162
Llorca CM, Potschin M, Zentgraf U (2014) bZIPs and WRKYs: two large transcription factor families executing two different functional strategies. Front Plant Sci 5:169

Lloret A, Conejero A, Leida C et al (2017) Dual regulation of water retention and cell growth by a stress-associated protein (SAP) gene in Prunus. Sci Rep 7:332

Lu Y, Chen X, Wu Y et al (2013) Directly transforming PCR-amplified DNA fragments into plant cells is a versatile system that facilitates the transient expression assay. PLoS ONE 8:e57171

Lu X, Zhang X, Duan H et al (2017) Three stress-responsive NAC transcription factors from Populus euphratica differentially regulate salt and drought tolerance in transgenic plants. Physiol Plant 162:73-97

Lu P, Magwanga RO, Lu H et al (2018) A novel G-protein-coupled receptors gene from upland cotton enhances salt stress tolerance in transgenic Arabidopsis. Genes (Basel) 9:209

Luo Q, Wei Q, Wang R et al (2017) BdCIPK31, a calcineurin b-like protein-interacting protein kinase, regulates plant response to drought and salt stress. Front Plant Sci 8:1184

Lynch T, Erickson BJ, Finkelstein RR (2012) Direct interactions of ABA-insensitive (ABI)-clade protein phosphatase (PP) 2Cs with calcium-dependent protein kinases and $\mathrm{ABA}$ response elementbinding bZIPs may contribute to turning off ABA response. Plant Mol Biol 80:647-658

Ma Y, Szostkiewicz I, Korte A et al (2009) Regulators of PP2C phosphatase activity function as abscisic acid sensors. Science (80-) 324:1064-1068

Malik AA, Veltri M, Boddington KF et al (2017) Genome analysis of conserved dehydrin motifs in vascular plants. Front Plant Sci 8:709

Manfre AJ, Lanni LM, Marcotte WR (2006) The Arabidopsis group 1 LATE EMBRYOGENESIS ABUNDANT protein ATEM6 is required for normal seed development. Plant Physiol 140:140-149

Manik SM, Shi S, Mao J et al (2015) The calcium sensor CBL-CIPK is involved in plant's response to abiotic stresses. Int J Genom 11:1-10

Mao X, Chen S, Li A et al (2014) Novel NAC transcription factor TaNAC67 confers enhanced multi-abiotic stress tolerances in Arabidopsis. PLoS ONE 9:e84359

Mao H, Wang H, Liu S et al (2015) A transposable element in a NAC gene is associated with drought tolerance in maize seedlings. Nat Commun 6:8326

Mao H, Yu L, Han R et al (2016) ZmNAC55, a maize stress-responsive NAC transcription factor, confers drought resistance in transgenic Arabidopsis. Plant Physiol Biochem 105:55-66

Martins CPS, Neves DM, Cidade LC et al (2017) Expression of the citrus CsTIP2; 1 gene improves tobacco plant growth, antioxidant capacity and physiological adaptation under stress conditions. Planta 245:951-963

Masand S, Yadav SK (2016) Overexpression of MuHSP70 gene from Macrotyloma uniflorum confers multiple abiotic stress tolerance in transgenic Arabidopsis thaliana. Mol Biol Rep 43:53-64

Maurel C, Verdoucq L, Luu D-T, Santoni V (2008) Plant aquaporins: membrane channels with multiple integrated functions. Annu Rev Plant Biol 59:595-624

Maurel C, Boursiac Y, Luu D-T et al (2015) Aquaporins in plants. Physiol Rev 95:1321-1358

Misra S, Wu Y, Venkataraman G et al (2007) Heterotrimeric G-protein complex and G-protein-coupled receptor from a legume (Pisum sativum): role in salinity and heat stress and cross-talk with phospholipase C. Plant J 51:656-669

Mittler R (2002) Oxidative stress, antioxidants and stress tolerance. Trends Plant Sci 7:405-410 
Miyakawa T, Fujita Y, Yamaguchi-Shinozaki K, Tanokura M (2013) Structure and function of abscisic acid receptors. Trends Plant Sci 18:259-266

Moustafa K, AbuQamar S, Jarrar M et al (2014) MAPK cascades and major abiotic stresses. Plant Cell Rep 33:1217-1225

Mukhopadhyay A, Vij S, Tyagi AK (2004) Overexpression of a zincfinger protein gene from rice confers tolerance to cold, dehydration, and salt stress in transgenic tobacco. Proc Natl Acad Sci USA 101:6309-6314

Mundy J, Chua N-H (1988) Abscisic acid and water-stress induce the expression of a novel rice gene. EMBO J 7:2279-2286

Munemasa S, Hauser F, Park J et al (2015) Mechanisms of abscisic acid-mediated control of stomatal aperture. Curr Opin Plant Biol 28:154-162

Munir S, Liu H, Xing Y et al (2016) Overexpression of calmodulin-like (ShCML44) stress-responsive gene from Solanum habrochaites enhances tolerance to multiple abiotic stresses. Sci Rep 6:31772

Nambara E, Marion-Poll A (2005) Abscisic acid biosynthesis and catabolism. Annu Rev Plant Biol 56:165-185

Nelson DE, Raghothama KG, Singh NK et al (1992) Analysis of structure and transcriptional activation of an osmotin gene. Plant Mol Biol 19:577-588

$\mathrm{Ng}$ LM (2016) Abscisic acid signalling as a target for enhancing drought tolerance. In: Shanker A, Shanker C (eds) Abiotic and biotic stress in plants-recent advances and future perspectives. InTech, London, p 22

Ning J, Li X, Hicks LM, Xiong L (2010) A Raf-like MAPKKK gene DSM1 mediates drought resistance through reactive oxygen species scavenging in rice. Plant Physiol 152:876-890

Ning W, Zhai H, Yu J et al (2017) Overexpression of Glycine soja WRKY20 enhances drought tolerance and improves plant yields under drought stress in transgenic soybean. Mol Breed 37:19

Noman A, Liu Z, Aqeel M et al (2017) Basic leucine zipper domain transcription factors: the vanguards in plant immunity. Biotechnol Lett 39:1779-1791

Nongpiur R, Soni P, Karan R et al (2012) Histidine kinases in plants: cross talk between hormone and stress responses. Plant Signal Behav 7:1230-1237

Nouri MZ, Komatsu S (2013) Subcellular protein overexpression to develop abiotic stress tolerant plants. Front Plant Sci 4:2

Ohama N, Sato H, Shinozaki K, Yamaguchi-Shinozaki K (2017) Transcriptional regulatory network of plant heat stress response. Trends Plant Sci 22:53-65

Osakabe Y, Yamaguchi-Shinozaki K, Shinozaki K, Tran LSP (2013) Sensing the environment: key roles of membrane-localized kinases in plant perception and response to abiotic stress. J Exp Bot 64:445-458

Pandey GK, Pandey A, Prasad M, Böhmer M (2016) Abiotic stress signaling in plants: functional genomic intervention. Front Plant Sci 7:68

Parent B, Turc O, Gibon Y et al (2010) Modelling temperaturecompensated physiological rates, based on the co-ordination of responses to temperature of developmental processes. J Exp Bot 61:2057-2069

Park WJ, Campbell BT (2015) Aquaporins as targets for stress tolerance in plants: genomic complexity and perspectives. Turk J Bot 39:879-886

Park S-Y, Fung P, Nishimura N et al (2009) Abscisic acid inhibits type $2 \mathrm{C}$ protein phosphatases via the PYR/PYL family of START proteins. Science (80-) 324:1068-1071

Park YC, Chapagain S, Jang CS (2018) A negative regulator in response to salinity in rice: Oryza sativa Salt-, ABA-and Drought-induced RING finger protein 1 (OsSADR1). Plant Cell Physiol 59:575-589
Pedrosa AM, Martins CDPS, Gonçalves LP et al (2015) Late embryogenesis abundant (LEA) constitutes a large and diverse family of proteins involved in development and abiotic stress responses in sweet orange (Citrus sinensis L. Osb.). PLoS ONE 10:e0145785

Pérez-Clemente RM, Vives V, Zandalinas SI et al (2013) Biotechnological approaches to study plant responses to stress. Biomed Res Int. https://doi.org/10.1155/2013/654120

Perochon A, Aldon D, Galaud J-P, Ranty B (2011) Calmodulin and calmodulin-like proteins in plant calcium signaling. Biochimie 93:2048-2053

Pham J, Liu J, Bennett MH et al (2012) Arabidopsis histidine kinase 5 regulates salt sensitivity and resistance against bacterial and fungal infection. New Phytol 194:168-180

Phukan UJ, Jeena GS, Shukla RK (2016) WRKY transcription factors: molecular regulation and stress responses in plants. Front Plant Sci 7:760

Pornsiriwong W, Estavillo GM, Chan KX et al (2017) A chloroplast retrograde signal, 3'-phosphoadenosine 5'-phosphate, acts as a secondary messenger in abscisic acid signaling in stomatal closure and germination. ELife 6:e23361. https://doi.org/10.7554/ eLife. 23361

Prasad PVV, Staggenborg SA, Ristic Z (2008) Impacts of drought and/ or heat stress on physiological, developmental, growth, and yield processes of crop plants. In: Response of crops to limited water: Understanding and modeling water stress effects on plant growth processes (response of crops), pp 301-355

Puhakainen T, Hess MW, Mäkelä P et al (2004) Overexpression of multiple dehydrin genes enhances tolerance to freezing stress in Arabidopsis. Plant Mol Biol 54:743-753

Puranik S, Sahu PP, Srivastava PS, Prasad M (2012) NAC proteins: regulation and role in stress tolerance. Trends Plant Sci 17:369-381

Qiao B, Zhang Q, Liu D et al (2015) A calcium-binding protein, rice annexin OsANN1, enhances heat stress tolerance by modulating the production of $\mathrm{H}_{2} \mathrm{O}_{2}$. J Exp Bot 66:5853-5866

Rahnama A, Poustini K, Tavakkol-Afshari R, Tavakoli A (2010) Growth and stomatal responses of bread wheat genotypes in tolerance to salt stress. Int J Biol Life Sci 6:216-221

Rakhra G, Sharma AD (2012) Expression analysis of some boiling stable proteins (Hydrophilins) under combined effect of drought stress and heat shock in drought tolerant and susceptible cultivars of Triticum aestivum. Agric Agric Pract Sci J 81:1-10

Ranty B, Aldon D, Cotelle V et al (2016) Calcium sensors as key hubs in plant responses to biotic and abiotic stresses. Front Plant Sci 7:327

Rasul I, Nadeem H, Siddique MH et al (2017) Plants sensory-response mechanisms for salinity and heat stress. JAPS J Anim Plant Sci 27:490-502

Reddy ASN, Ali GS, Celesnik H, Day IS (2011) Coping with stresses: roles of calcium-and calcium/calmodulin-regulated gene expression. Plant Cell 23:2010-2032

Renaut J, Hoffmann L, Hausman J (2005) Biochemical and physiological mechanisms related to cold acclimation and enhanced freezing tolerance in poplar plantlets. Physiol Plant 125:82-94

Reuscher S, Akiyama M, Mori C et al (2013) Genome-wide identification and expression analysis of aquaporins in tomato. PLoS ONE 8:e79052

Rexroth S, Mullineaux CW, Ellinger D et al (2011) The plasma membrane of the cyanobacterium Gloeobacter violaceus contains segregated bioenergetic domains. Plant Cell 23:2379-2390

Reyes JL, Rodrigo M, Colmener-Flores JM et al (2005) Hydrophilins from distant organisms can protect enzymatic activities from water limitation effects in vitro. Plant Cell Environ 28:709-718

Rizhsky L, Liang H, Shuman J et al (2004) When defense pathways collide. The response of Arabidopsis to a combination of drought and heat stress. Plant Physiol 134:1683-1696 
Rollins JA, Habte E, Templer SE et al (2013) Leaf proteome alterations in the context of physiological and morphological responses to drought and heat stress in barley (Hordeum vulgare L.). J Exp Bot 64:3201-3212

Rosenzweig C, Elliott J, Deryng D et al (2014) Assessing agricultural risks of climate change in the 21 st century in a global gridded crop model intercomparison. Proc Natl Acad Sci 111:3268-3273

Roy S (2016) Function of MYB domain transcription factors in abiotic stress and epigenetic control of stress response in plant genome. Plant Signal Behav 11:e1117723

Rushton PJ, Bokowiec MT, Han S et al (2008) Tobacco transcription factors: novel insights into transcriptional regulation in the Solanaceae. Plant Physiol 147:280-295

Saad RB, Zouari N, Ben Ramdhan W et al (2010) Improved drought and salt stress tolerance in transgenic tobacco overexpressing a novel A20/AN1 zinc-finger "AlSAP" gene isolated from the halophyte grass Aeluropus littoralis. Plant Mol Biol 72:171

Saibo NJ, Lourenço T, Oliveira MM (2009) Transcription factors and regulation of photosynthetic and related metabolism under environmental stresses. Ann Bot 103:609-623

Sakuraba Y, Kim Y-S, Han S-H et al (2015) The Arabidopsis transcription factor NAC016 promotes drought stress responses by repressing AREB1 transcription through a trifurcate feed-forward regulatory loop involving NAP. Plant Cell 27:1771-1787

Šamajová O, Plíhal O, Al-Yousif M et al (2013) Improvement of stress tolerance in plants by genetic manipulation of mitogen-activated protein kinases. Biotechnol Adv 31:118-128

Sato A, Sato Y, Fukao Y et al (2009) Threonine at position 306 of the KAT1 potassium channel is essential for channel activity and is a target site for ABA-activated SnRK2/OST1/SnRK2. 6 protein kinase. Biochem J 424:439-448

Schaller GE, Kieber JJ, Shiu S-H (2008) Two-component signaling elements and histidyl-aspartyl phosphorelays. Arab B 6:e0112

Schulz P, Herde M, Romeis T (2013) Calcium-dependent protein kinases: hubs in plant stress signaling and development. Plant Physiol 163:523-530

Sehgal A, Sita K, Kumar J et al (2017a) Effects of drought, heat and their interaction on the growth, yield and photosynthetic function of lentil (Lens culinaris Medikus) genotypes varying in heat and drought sensitivity. Front Plant Sci 8:1-22

Sehgal A, Sita K, Kumar J et al (2017b) Effects of drought, heat and their interaction on the growth, yield and photosynthetic function of lentil (Lens culinaris Medikus) genotypes varying in heat and drought sensitivity. Front Plant Sci 8:1776

Sewelam N, Oshima Y, Mitsuda N, OHME-TAKAGI M (2014) A step towards understanding plant responses to multiple environmental stresses: a genome-wide study. Plant Cell Environ 37:2024-2035

Shanker AK, Maheswari M, Yadav SK et al (2014) Drought stress responses in crops. Funct Integr Genom 14:11-22

Shao H-B, Chu L-Y, Jaleel CA et al (2009) Understanding water deficit stress-induced changes in the basic metabolism of higher plantsbiotechnologically and sustainably improving agriculture and the ecoenvironment in arid regions of the globe. Crit Rev Biotechnol 29:131-151

Shao H, Wang H, Tang X (2015) NAC transcription factors in plant multiple abiotic stress responses: progress and prospects. Front Plant Sci 6:902

Sharma AD, Kaur P (2009) Combined effect of drought stress and heat shock on cyclophilin protein expression in Triticum aestivum. Gen Appl Plant Physiol 35:88-92

Shen H, Zhong X, Zhao F et al (2015) Overexpression of receptorlike kinase ERECTA improves thermotolerance in rice and tomato. Nat Biotechnol 33:996

Shi J, An H-L, Zhang L et al (2010) GhMPK7, a novel multiple stress-responsive cotton group C MAPK gene, has a role in broad spectrum disease resistance and plant development. Plant Mol Biol 74:1-17

Shi H, Ye T, Zhu J-K, Chan Z (2014) Constitutive production of nitric oxide leads to enhanced drought stress resistance and extensive transcriptional reprogramming in Arabidopsis. J Exp Bot 65:4119-4131

Shih M-D, Hoekstra FA, Hsing Y-IC (2008) Late embryogenesis abundant proteins. In: Kader JC, Delseny M (eds) Advances in botanical research. Elsevier, pp 211-225

Shiraya T, Mori T, Maruyama T et al (2015) Golgi/plastid-type manganese superoxide dismutase involved in heat-stress tolerance during grain filling of rice. Plant Biotechnol J 13:1251-1263

Shiu S-H, Karlowski WM, Pan R et al (2004) Comparative analysis of the receptor-like kinase family in Arabidopsis and rice. Plant Cell 16:1220-1234

Shu Y, Liu Y, Zhang J et al (2016) Genome-wide analysis of the AP2/ ERF superfamily genes and their responses to abiotic stress in Medicago truncatula. Front Plant Sci 6:124

Silvestri C, Celletti S, Cristofori V et al (2017) Olive (Olea europaea L.) plants transgenic for tobacco osmotin gene are less sensitive to in vitro-induced drought stress. Acta Physiol Plant 39:229

Simeunovic A, Mair A, Wurzinger B, Teige M (2016) Know where your clients are: subcellular localization and targets of calciumdependent protein kinases. J Exp Bot 67:3855-3872

Singh NK, Nelson DE, Kuhn D et al (1989) Molecular cloning of osmotin and regulation of its expression by $\mathrm{ABA}$ and adaptation to low water potential. Plant Physiol 90:1096-1101

Singh A, Kushwaha HR, Soni P et al (2015) Tissue specific and abiotic stress regulated transcription of histidine kinases in plants is also influenced by diurnal rhythm. Front Plant Sci 6:711

Sinha AK, Ara H (2014) Conscientiousness of mitogen activated protein kinases in acquiring tolerance for abiotic stresses in plants. Proc Indian Natl Sci Acad 80:211-219

Sinha AK, Jaggi M, Raghuram B, Tuteja N (2011) Mitogen-activated protein kinase signaling in plants under abiotic stress. Plant Signal Behav 6:196-203

Sita K, Sehgal A, Kumar J et al (2017) Identification of high-temperature tolerant lentil (Lens culinaris Medik.) genotypes through leaf and pollen traits. Front Plant Sci 8:1-27

Sornaraj P, Luang S, Lopato S, Hrmova M (2016) Basic leucine zipper (bZIP) transcription factors involved in abiotic stresses: a molecular model of a wheat bZIP factor and implications of its structure in function. Biochim Biophys Acta (BBA)-Gen Subj 1860:46-56

Sun L, Liu Y, Kong X et al (2012) ZmHSP16. 9, a cytosolic class I small heat shock protein in maize (Zea mays), confers heat tolerance in transgenic tobacco. Plant Cell Rep 31:1473-1484

Susan J, Fatemeh R, Latifeh P (2013) Effect of abiotic stresses on histidine kinases gene expression in Zea mays L. cv. SC. 704. J Stress Physiol Biochem 9:124-135

Suzuki N (2016) Hormone signaling pathways under stress combinations. Plant Signal Behav 11:e1247139

Suzuki N, Miller G, Salazar C et al (2013) Temporal-spatial interaction between reactive oxygen species and abscisic acid regulates rapid systemic acclimation in plants. Plant Cell 25:3553-3569

Takeuchi K, Gyohda A, Tominaga M et al (2016) RSOsPR10 expression in response to environmental stresses is regulated antagonistically by jasmonate/ethylene and salicylic acid signaling pathways in rice roots. Plant Cell Physiol 52:1686-1696

Tang N, Zhang H, Li X et al (2012) Constitutive activation of transcription factor OsbZIP46 improves drought tolerance in rice. Plant Physiol 158:111

Team CW, Pachauri RK, Meyer LA (2014) IPCC, 2014: climate change 2014: synthesis report. Contribution of Working Groups I. II III to Fifth Assess Rep Intergov panel Clim Chang IPCC, Geneva, Switz 151 
Thirumalaikumar VP, Devkar V, Mehterov N et al (2017) NAC transcription factor JUNGBRUNNEN1 enhances drought tolerance in tomato. Plant Biotechnol J 16:354-366

Tian X, Wang Z, Li X et al (2015) Characterization and functional analysis of pyrabactin resistance-like abscisic acid receptor family in rice. Rice 8:28

Tran L-SP, Urao T, Qin F et al (2007) Functional analysis of AHK1/ ATHK1 and cytokinin receptor histidine kinases in response to abscisic acid, drought, and salt stress in Arabidopsis. Proc Natl Acad Sci 104:20623-20628

Tran L-SP, Nishiyama R, Yamaguchi-Shinozaki K, Shinozaki K (2010) Potential utilization of NAC transcription factors to enhance abiotic stress tolerance in plants by biotechnological approach. GM Crops 1:32-39

Tripathi P, Rabara RC, Rushton PJ (2014) A systems biology perspective on the role of WRKY transcription factors in drought responses in plants. Planta 239:255-266

Tu M, Wang X, Huang L et al (2016) Expression of a grape bZIP transcription factor, VqbZIP39, in transgenic Arabidopsis thaliana confers tolerance of multiple abiotic stresses. Plant Cell Tissue Organ Cult 125:537-551

Tunnacliffe A, Hincha DK, Leprince O, Macherel D (2010) LEA proteins: versatility of form and function. In: Lubzens E, Cerda J, Clarke M (eds) Dormancy and resistance in harsh environments. Topics in current genetics, vol 21. Springer, Berlin, pp 91-108

Tuteja N, Gill SS (2016) Abiotic stress response in plants. Wiley, Hoboken

Tuteja N, Sopory SK (2008) Plant signaling in stress: G-protein coupled receptors, heterotrimeric G-proteins and signal coupling via phospholipases. Plant Signal Behav 3:79-86

Udvardi MK, Kakar K, Wandrey M et al (2007) Legume transcription factors: global regulators of plant development and response to the environment. Plant Physiol 144:538-549

Ullah H, Chen J-G, Wang S, Jones AM (2002) Role of a heterotrimeric $\mathrm{G}$ protein in regulation of Arabidopsis seed germination. Plant Physiol 129:897-907

Umezawa T, Sugiyama N, Takahashi F et al (2013) Genetics and phosphoproteomics reveal a protein phosphorylation network in the abscisic acid signaling pathway in Arabidopsis thaliana. Sci Signal 6:rs8

Urano D, Jones AM (2014) Heterotrimeric G protein-coupled signaling in plants. Annu Rev Plant Biol 65:365-384

Vahisalu T, Puzõrjova I, Brosché M et al (2010) Ozone-triggered rapid stomatal response involves the production of reactive oxygen species, and is controlled by SLAC1 and OST1. Plant J 62:442-453

Van Loon LC, Van Strien EA (1999) The families of pathogenesisrelated proteins, their activities, and comparative analysis of PR-1 type proteins. Physiol Mol Plant Pathol 55:85-97

Varshney RK, Chen W, Li Y et al (2012) Draft genome sequence of pigeonpea (Cajanus cajan), an orphan legume crop of resource-poor farmers. Nat Biotechnol 30:83

Varshney RK, Song C, Saxena RK et al (2013) Draft genome sequence of chickpea (Cicer arietinum) provides a resource for trait improvement. Nat Biotechnol 31:240

Verma AK, Deepti S (2016) Abiotic stress and crop improvement: current scenario. Adv Plants Agric Res 4:149

Vij S, Tyagi AK (2006) Genome-wide analysis of the stress associated protein (SAP) gene family containing A20/AN1 zinc-finger (s) in rice and their phylogenetic relationship with Arabidopsis. Mol Genet Genom 276:565-575

Vij S, Tyagi AK (2008) A20/AN1 zinc-finger domain-containing proteins in plants and animals represent common elements in stress response. Funct Integr Genom 8:301-307
Viktorova J, Krasny L, Kamlar M et al (2012) Osmotin, a pathogenesisrelated protein. Curr Protein Pept Sci 13:672-681

Virdi AS, Singh S, Singh P (2015) Abiotic stress responses in plants: roles of calmodulin-regulated proteins. Front Plant Sci 6:809

Vishwakarma K, Upadhyay N, Kumar N et al (2017) Abscisic acid signaling and abiotic stress tolerance in plants: a review on current knowledge and future prospects. Front Plant Sci 8:161

Wahid A, Close TJ (2007) Expression of dehydrins under heat stress and their relationship with water relations of sugarcane leaves. Biol Plant 51:104-109

Wahid A, Gelani S, Ashraf M, Foolad MR (2007) Heat tolerance in plants: an overview. Environ Exp Bot 61:199-223

Wang X-Q, Ullah H, Jones AM, Assmann SM (2001) G protein regulation of ion channels and abscisic acid signaling in Arabidopsis guard cells. Science 292:2070-2072

Wang W, Vinocur B, Shoseyov O, Altman A (2004) Role of plant heatshock proteins and molecular chaperones in the abiotic stress response. Trends Plant Sci 9:244-252

Wang J, Sun N, Deng T et al (2014a) Genome-wide cloning, identification, classification and functional analysis of cotton heat shock transcription factors in cotton (Gossypium hirsutum). BMC Genom 15:961

Wang M, Li P, Li C et al (2014b) SiLEA14, a novel atypical LEA protein, confers abiotic stress resistance in foxtail millet. BMC Plant Biol 14:290

Wang X, Zeng J, Li Y et al (2015) Expression of TaWRKY44, a wheat WRKY gene, in transgenic tobacco confers multiple abiotic stress tolerances. Front Plant Sci 6:615

Wang C, Lu W, He X et al (2016a) The cotton mitogen-activated protein kinase kinase 3 functions in drought tolerance by regulating stomatal responses and root growth. Plant Cell Physiol 57:1629-1642

Wang H, Wang H, Shao H, Tang X (2016b) Recent advances in utilizing transcription factors to improve plant abiotic stress tolerance by transgenic technology. Front Plant Sci 7:67

Wang X, Yan B, Shi M et al (2016c) Overexpression of a Brassica campestris HSP70 in tobacco confers enhanced tolerance to heat stress. Protoplasma 253:637-645

Wang C, Lu G, Hao Y et al (2017a) ABP9, a maize bZIP transcription factor, enhances tolerance to salt and drought in transgenic cotton. Planta 246:453-469

Wang L, Li Q-T, Lei Q et al (2017b) Ectopically expressing MdPIP1; 3 , an aquaporin gene, increased fruit size and enhanced drought tolerance of transgenic tomatoes. BMC Plant Biol 17:246

Wang L, Li Z, Lu M, Wang Y (2017c) ThNAC13, a NAC transcription factor from Tamarix hispida, confers salt and osmotic stress tolerance to transgenic tamarix and Arabidopsis. Front Plant Sci $8: 635$

Wang X, Zhang L, Zhang Y et al (2017d) Triticum aestivum WRAB18 functions in plastids and confers abiotic stress tolerance when overexpressed in Escherichia coli and Nicotiania benthamiana. PLOS ONE 12:e0171340

Wei S, Hu W, Deng X et al (2014) A rice calcium-dependent protein kinase OsCPK9 positively regulates drought stress tolerance and spikelet fertility. BMC Plant Biol 14:133

Wei Q, Luo Q, Wang R et al (2017) A Wheat R2R3-type MYB transcription factor TaODORANT1 positively regulates drought and salt Stress responses in transgenic Tobacco plants. Front Plant Sci 8:1374

Wohlbach DJ, Quirino BF, Sussman MR (2008) Analysis of the Arabidopsis histidine kinase ATHK1 reveals a connection between vegetative osmotic stress sensing and seed maturation. Plant Cell 20:1101-1117

Wu L, Zu X, Zhang $\mathrm{H}$ et al (2015) Overexpression of ZmMAPK1 enhances drought and heat stress in transgenic Arabidopsis thaliana. Plant Mol Biol 88:429-443 
Xiang Y, Tang N, Du H et al (2008) Characterization of OsbZIP23 as a key player of bZIP transcription factor family for conferring ABA sensitivity and salinity and drought tolerance in rice. Plant Physiol 148:1938-1952

Xie R, Zheng L, Deng L et al (2014) The role of R2R3MYB transcription factors in plant stress tolerance. J Anim Plant Sci 24:1821-1833

Xin H, Zhang H, Zhong X et al (2017) Over-expression of LlHsfA2b, a lily heat shock transcription factor lacking trans-activation activity in yeast, can enhance tolerance to heat and oxidative stress in transgenic Arabidopsis seedlings. Plant Cell Tissue Organ Cult 130:617-629

Xiong L, Zhu J (2002) Molecular and genetic aspects of plant responses to osmotic stress. Plant Cell Environ 25:131-139

$\mathrm{Xu}$ C, Huang B (2012) Comparative analysis of proteomic responses to single and simultaneous drought and heat stress for two Kentucky bluegrass cultivars. Crop Sci 52:1246-1260

Xu G-Y, Rocha PSCF, Wang M-L et al (2011) A novel rice calmodulinlike gene, OsMSR2, enhances drought and salt tolerance and increases ABA sensitivity in Arabidopsis. Planta 234:47-59

Xu C, Wang M, Zhou L et al (2013) Heterologous expression of the wheat aquaporin gene TaTIP2; 2 compromises the abiotic stress tolerance of Arabidopsis thaliana. PLoS ONE 8:e79618

Xu D-B, Gao S-Q, Ma Y-Z et al (2014a) ABI-like transcription factor gene TaABL1 from wheat improves multiple abiotic stress tolerances in transgenic plants. Funct Integr Genom 14:717-730

Xu Y, Hu W, Liu J et al (2014b) A banana aquaporin gene, MaPIP1; 1, is involved in tolerance to drought and salt stresses. BMC Plant Biol 14:59

$\mathrm{Xu} \mathrm{K}$, Chen S, Li T et al (2015) OsGRAS23, a rice GRAS transcription factor gene, is involved in drought stress response through regulating expression of stress-responsive genes. BMC Plant Biol $15: 141$

Yadav DK, Tuteja N (2011) Rice G-protein coupled receptor (GPCR) In silico analysis and transcription regulation under abiotic stress. Plant Signal Behav 6:1079-1086

Yamaguchi-Shinozaki K, Shinozaki K (2006) Transcriptional regulatory networks in cellular responses and tolerance to dehydration and cold stresses. Annu Rev Plant Biol 57:781-803

Yang Y-G, Lv W-T, Li M-J et al (2013) Maize membrane-bound transcription factor Zmbzip17 is a key regulator in the cross-talk of ER quality control and ABA signaling. Plant Cell Physiol 54:2020-2033

Yang G, Yu L, Zhang K et al (2017) A ThDREB gene from Tamarix hispida improved the salt and drought tolerance of transgenic tobacco and T. hispida. Plant Physiol Biochem 113:187-197

Ye Y, Ding Y, Jiang Q et al (2017) The role of receptor-like protein kinases (RLKs) in abiotic stress response in plants. Plant Cell Rep 36:235-242

Yin X, Huang L, Wang M et al (2017) OsDSR-1, a calmodulin-like gene, improves drought tolerance through scavenging of reactive oxygen species in rice (Oryza sativa L.). Mol Breed 37(6):75

Yoshida T, Fujita Y, Sayama H et al (2010) AREB1, AREB2, and $\mathrm{ABF} 3$ are master transcription factors that cooperatively regulate ABRE-dependent ABA signaling involved in drought stress tolerance and require ABA for full activation. Plant J 61:672-685

You J, Zong W, Hu H et al (2014) A SNAC1-regulated protein phosphatase gene OsPP18 modulates drought and oxidative stress tolerance through ABA-independent reactive oxygen species scavenging in rice. Plant Physiol 166:114

Yu Q, An L, Li W (2014) The CBL-CIPK network mediates different signaling pathways in plants. Plant Cell Rep 33:203-214

Yu J, Lai Y, Wu X et al (2016) Overexpression of OsEm1 encoding a group I LEA protein confers enhanced drought tolerance in rice. Biochem Biophys Res Commun 478:703-709
Yu X, Takebayashi A, Demura T, Ohtani M (2017) Differential expression of poplar sucrose nonfermenting1-related protein kinase 2 genes in response to abiotic stress and abscisic acid. J Plant Res 130:929-940

Yue C, Cao H, Wang L et al (2014) Molecular cloning and expression analysis of tea plant aquaporin (AQP) gene family. Plant Physiol Biochem 83:65-76

Zandalinas SI, Rivero RM, Martínez V et al (2016) Tolerance of citrus plants to the combination of high temperatures and drought is associated to the increase in transpiration modulated by a reduction in abscisic acid levels. BMC Plant Biol 16:1-16

Zandalinas SI, Sales C, Beltrán J et al (2017) Activation of secondary metabolism in citrus plants is associated to sensitivity to combined drought and high temperatures. Front Plant Sci 7:1954

Zandalinas SI, Mittler R, Balfagón D et al (2018) Plant adaptations to the combination of drought and high temperatures. Physiol Plant 162:2-12

Zargar SM, Nagar P, Deshmukh R et al (2017) Aquaporins as potential drought tolerance inducing proteins: towards instigating stress tolerance. J Proteom 169:233-238

Zeng H, Xu L, Singh A et al (2015) Involvement of calmodulin and calmodulin-like proteins in plant responses to abiotic stresses. Front Plant Sci 6:600

Zhang Y (2014) Identification and characterization of the grape WRKY family. Biomed Res Int 14:787680

Zhang YX, Chen L (2017) Overexpression of the receptor-like kinase gene OsNRRB enhances drought-stress tolerance in rice. Euphytica 213:86

Zhang J, Jia W, Yang J, Ismail AM (2006) Role of ABA in integrating plant responses to drought and salt stresses. Field Crop Res 97:111-119

Zhang H, Liang W, Yang X et al (2010) Carbon starved anther encodes a MYB domain protein that regulates sugar partitioning required for rice pollen development. Plant Cell 22:672-689

Zhang L, Xi D, Li S et al (2011) A cotton group C MAP kinase gene, GhMPK2, positively regulates salt and drought tolerance in tobacco. Plant Mol Biol 77:17-31

Zhang T, Chen S, Harmon AC (2014) Protein phosphorylation in stomatal movement. Plant Signal Behav 9:e972845

Zhang J, Li Y, Jia H-X et al (2015) The heat shock factor gene family in Salix suchowensis: a genome-wide survey and expression profiling during development and abiotic stresses. Front Plant Sci 6:74

Zhang X, Zhang B, Li MJ et al (2016) OsMSR15 encoding a rice $\mathrm{C} 2 \mathrm{H} 2$-type zinc finger protein confers enhanced drought tolerance in transgenic Arabidopsis. J Plant Biol 59:271-281

Zhao Y, Chan Z, Xing L et al (2013a) The unique mode of action of a divergent member of the ABA-receptor protein family in ABA and stress signaling. Cell Res 23:1380

Zhao Y, Liu W, Xu Y-P et al (2013b) Genome-wide identification and functional analyses of calmodulin genes in Solanaceous species. BMC Plant Biol 13:70

Zhao Y, Chan Z, Gao J et al (2016) ABA receptor PYL9 promotes drought resistance and leaf senescence. Proc Natl Acad Sci 113:1949-1954

Zhou W, Jia C-G, Wu X et al (2016) ZmDBF3, a novel transcription factor from maize (Zea mays L.), is involved in multiple abiotic stress tolerance. Plant Mol Biol Rep 34:353-364

Zhu JK (2002) Salt and drought stress signal transduction in plants. Annu Rev Plant Biol 53:247-273

Zhu J-K (2016) Abiotic stress signaling and responses in plants. Cell 167:313-324

Zhu X, Thalor SK, Takahashi Y et al (2012) An inhibitory effect of the sequence-conserved upstream open-reading frame on the translation of the main open-reading frame of HsfB1 transcripts in Arabidopsis. Plant Cell Environ 35:2014-2030 
Zhu X, Dunand C, Snedden W, Galaud J-P (2015) CaM and CML emergence in the green lineage. Trends Plant Sci 20:483-489

Zlatev Z, Lidon FC (2012) An overview on drought induced changes in plant growth, water relations and photosynthesis. Emir J Food Agric 24:57-72

Zong J-M, Li X-W, Zhou Y-H et al (2016) The AaDREB1 transcription factor from the cold-tolerant plant Adonis amurensis enhances abiotic stress tolerance in transgenic plant. Int J Mol Sci 17:611

Zou Y, Liu X, Wang Q et al (2014) OsRPK1, a novel leucine-rich repeat receptor-like kinase, negatively regulates polar auxin transport and root development in rice. Biochim Biophys Acta (BBA) Gen Subj 1840:1676-1685

Publisher's Note Springer Nature remains neutral with regard to jurisdictional claims in published maps and institutional affiliations. 